\title{
Preparation and Characterization of Dutasteride-loaded Nanostructured Lipid Carriers coated with Stearic Acid-Chitosan Oligomer for Topical Delivery
}

\author{
Norhayati Mohamed Noor ${ }^{1,2}$, Khalid Sheikh ${ }^{1}$, Satyanarayana Somavarapu ${ }^{1}$, Kevin MG \\ Taylor $^{1}$ \\ ${ }^{1}$ Department of Pharmaceutics, UCL School of Pharmacy, 29-39 Brunswick Square, \\ London WC1N 1AX, United Kingdom \\ ${ }^{2}$ Institute of Bioproduct Development (N22), Universiti Teknologi Malaysia, 81310 \\ UTM Johor Bahru, Johor, Malaysia
}

Corresponding authors: norhayati.noor.13@ucl.ac.uk, kevin.taylor@ucl.ac.uk,

\begin{abstract}
Dutasteride, used for treating benign prostate hyperplasia $(\mathrm{BPH})$, promotes hair growth. To enhance delivery to the hair follicles and reduce systemic effects, in this study dutasteride has been formulated for topical application, in a nanostructured lipid carrier (NLC) coated with chitosan oligomer-stearic acid (CSO-SA). CSO-SA has been successfully synthesized, as confirmed using ${ }^{1} \mathrm{H}$ NMR and FTIR. Formulation of dutasteride-loaded nanostructured lipid carriers (DST-NLCs) was optimised using a $2^{3}$ full factorial design. This formulation was coated with different concentrations of stearic acid-chitosan solution. Coating DST-NLCs with 5\% SA-CSO increased mean size from $187.6 \pm 7.0 \mathrm{~nm}$ to $220.1 \pm 11.9 \mathrm{~nm}$, and modified surface charge, with zeta potentials being $-18.3 \pm 0.9 \mathrm{mV}$ and $+25.8 \pm 1.1 \mathrm{mV}$ for uncoated and coated DST-NLCs respectively. Transmission electron microscopy showed all formulations comprised approximately spherical particles. DST-NLCs, coated and uncoated with CSO-SA, exhibited particle size stability over 60 days, when stored at $4-8^{\circ} \mathrm{C}$. However, NLCs coated with CSO (without conjugation) showed aggregation when stored at $4-8^{\circ} \mathrm{C}$ after 30 days. The measured particle size for all formulations stored at $25^{\circ} \mathrm{C}$ suggested aggregation, which was greatest for DST-NLCs coated with 10\% CSO-SA and 5\% CSO. All nanoparticle formulations exhibited rapid release in an in vitro release study,
\end{abstract}


with uncoated NLCs exhibiting the fastest release rate. Using a Franz diffusion cell, no dutasteride permeated through pig ear skin after $48 \mathrm{~h}$, such that it was not detected in the receptor chamber for all samples. The amount of dutasteride in the skin was significantly different $(p<0.05)$ between DST-NLCs $\left(6.09 \pm 1.09 \mu \mathrm{g} / \mathrm{cm}^{2}\right)$ without coating and coated with $5 \%$ CSO-SA $\left(2.82 \pm 0.40 \mu \mathrm{g} / \mathrm{cm}^{2}\right), 10 \%$ CSO-SA $(2.70 \pm 0.35$ $\left.\mu \mathrm{g} / \mathrm{cm}^{2}\right)$ and CSO $\left(2.11 \pm 0.64 \mu \mathrm{g} / \mathrm{cm}^{2}\right.$. There was a significant difference $(p<0.05)$ in the cytotoxicity $\left(\mathrm{IC}_{50}\right)$ between dutasteride alone and in the nanoparticles. DST-NLCs coated and uncoated with CSO-SA increased the maximum non-toxic concentration by 20-fold compared to dutasteride alone. These studies indicate that a stearic acid-chitosan conjugate was successfully prepared, and modified the surface charge of DST-NLCs from negative to positive. These stable, less cytotoxic, positively-charged dutasterideloaded nanostructured lipid carriers, with stearic acid-chitosan oligomer conjugate, are appropriate for topical delivery and have potential for promotion of hair growth.

Keywords: alopecia, chitosan conjugation, dutasteride, nanostructured lipid carriers, topical delivery

\subsection{INTRODUCTION}

Androgenic alopecia (AGA, male-pattern baldness) affects almost 50\% of men during their lives [1]. Androgen is one of the prerequisites for male-pattern baldness [2]. Normally, patients with androgenic alopecia have higher levels of dihydrotestosterone (DHT) and 5- $\alpha$ reductase enzyme activity on their balding scalp area than those with a non-balding scalp area [3]. In hair-loss patients, testosterone is converted to DHT which results in miniaturization of the hair follicle and hair shedding [4]. There are two types of enzymes that contribute to androgenic alopecia: type I $5 \alpha$-reductase enzyme is present in the skin, including scalp, and type II is in the hair follicles and prostate [5]. Dutasteride (a type I and type II 5 $\alpha$-reductase inhibitor) is approved by the US Food and Drug Administration (FDA) for treating benign prostate hyperplasia (BPH), and has been studied for hair growth efficacy, with an oral dose of $0.5 \mathrm{mg}$ daily [6]. Dutasteride taken orally will reduce DHT levels throughout the body. In order to reduce the systemic effects of lowered DHT levels, such as diminished sexual desire, increased depression 
and ejaculation disorder [7,8], topical administration of dutasteride for treating AGA would be an appropriate drug-delivery strategy. Little research has been conducted using dutasteride for topical application. Ansari et al. [9] prepared nanoemulsions using different ratios of oleic acid and eucalyptus oil for delivery to the skin, in the size range of approximately 20-210 nm; no information on surface charge, entrapment efficiency or drug loading was provided. Madheswaran et al. [10] used monoolein to produce liquid crystalline nanoparticles of finasteride and dutasteride, surface-modified with chitosan (low molecular weight) to give a positive charge. The mean particle size was $239-259 \mathrm{~nm}$, with zeta potential +19.8 to $+48.5 \mathrm{mV}$. The surface-modified nanoparticles enhanced transdermal delivery of the 5- $\alpha$ reductase inhibitors, increasing permeation of finasteride and dutasteride. No stability studies were undertaken. Unlike most previous studies of dutasteride employing oral administration, this work aims to achieve local delivery of dutasteride, by formulation in a nanostructured lipid carrier (NLC) system for topical delivery to the skin/hair follicles. Previous studies have determined the transfollicular delivery of materials, including drugs using nanoparticles. Lademann et al. [11] found that dye-containing nanoparticles with a mean size of $320 \mathrm{~nm}$ penetrated deeper into the hair follicles, when massage was applied, than the dye similarly applied in non-nanoparticulate form. Blume-Peytavi et al., [12] compared the transfollicular and percutaneous delivery of a minoxidil foam. Minoxidil was detected in the blood faster when the hair follicle orifices were opened compared to the blocked hair follicle orifices, demonstrating more rapid drug delivery and transport via the follicular route. Patzelt et al., [13] reported that the penetration depth of particles into the hair follicles was dependent on their size; medium sized particles (643 and $646 \mathrm{~nm}$ ) penetrated deepest into porcine hair follicles, whereas smaller $(122 \mathrm{~nm}, 230 \mathrm{~nm}, 300 \mathrm{~nm}$ and $470 \mathrm{~nm})$ and larger particles $(860 \mathrm{~nm}, 920 \mathrm{~nm}$ and $100 \mathrm{~nm})$, penetrated the follicle, but to shorter depths.

Nanostructured lipid carriers (NLCs) were introduced by Muller et al., [14] subsequent to solid lipid nanoparticles (SLNs), to overcome some of the limitations associated with SLNs. NLCs can increase loading capacity, physical and chemical long-term stability and prolong release of incorporated molecules. They are also suitable for topical formulations [15]. Different types of solid lipid can be used in the production of SLNs and NLCs. The term of solid lipid includes fatty acids (e.g. myristic, stearic and palmitic acid), triglyceride (e.g. tripalmitin and tristearin), diglyceride (e.g. glyceryl behenate), 
monoglyceride (e.g. glyceryl monostearate), steroids (e.g. cholesterol) and waxes (e.g. cetyl palmitate and beeswax). Different types of solid lipid have different degrees of crystallization that may impact drug entrapment and loading, size and charge, and also efficacy. The lipid particle matrix is solid at both ambient and body temperatures [16] In this study, stearic acid has been chosen as a solid lipid due to its potential for promoting hair growth [17]. Previous research [18] has demonstrated that free fatty acids ( $\alpha$-linolenic, linoleic, palmitic, elaidic, oleic and stearic acid) are potent $5 \alpha$ reductase inhibitors and promote hair regrowth. Inclusion of stearic acid in the formulation, might have an additional effect with dutasteride for the promotion of hair growth. Due to the properties of dutasteride, which is poorly water soluble $(0.038$ $\mathrm{ng} / \mathrm{mL}$; Log $\mathrm{P}=5.09$ ) [19], NLCs would seem useful as a potential carrier. NLCs composed of biocompatible and biodegradable lipids have low toxicity and cytotoxicity, are suitable for topical application and have an occlusive effect on the skin, increasing skin hydration [20]. Mittal et al. [21] reported that NLCs with a size of approximately $300 \mathrm{~nm}$ were found in the transfollicular region of the skin. Hamishehkar et al. [22] found higher skin deposition of flutamide-loaded SLNs (volume mean diameter approximately $200 \mathrm{~nm}$ ) compared to flutamide hydroalcoholic. This higher accumulation of flutamide-SLNs in the hair follicles suggested a greater growth of new hair follicles based on the histological assessment

Chitosan, a naturally occurring polysaccharide, contains free amino groups, is cationic in neutral or basic $\mathrm{pH}$ conditions, and is commonly used for drug delivery applications, particularly where a positive charge is advantageous. Hair is negatively charged [23]; consequently, introducing a positive charge to nanoparticles may enhance targeting. It is also reported that due to the bioadhesive properties of chitosan, it may increase retention of the drug/carrier in the targeted area [24]. Taking this into account, DST-NLCs coated with a positively-charged, chitosan-based polymer have been investigated here for topical/transfollicular delivery.

In the present study, stearic acid was selected for use as a lipophilic ingredient and synthesized with chitosan to enhance the lipophilicity of the aqueous-soluble chitosan. The carboxylic group of stearic acid was reacted with the amine group from chitosan with addition of 1-ethyl-3-(3-dimethylaminopropyl) carbodiimide hydrochloride (EDC.HCl), creating the hydrophobic drug-delivery moiety. 
Therefore, it is suggested that when dutasteride is incorporated in the nanostructured lipid carrier (NLC), the drug will be entrapped in the hydrophobic region where surfactants are added to stabilize it. A solution of stearic acid-chitosan (CSOSA) having a positive charge will coat the nanoparticles.

The aim of this study is then to design and formulate a stable and less cytotoxic formulation of DST-NLCs coated with CSO-SA for the promotion of hair growth. This study anticipates that surface modification of DST-NLCs with CSO-SA would produce a slow release of the drugs in the skin/hair follicles with potential to reduce systemic effects.

\subsection{MATERIALS AND METHODS}

\subsection{Materials}

Stearic acid was purchased from Tokyo Chemical Industry (UK). Chitosan oligomer (CSO), Mwt <3000Da and dutasteride (purity >98.0\%) were obtained from Carbosynth (UK). Ethanol (96\% v/v analytical grade), 1-ethyl-3-(3-dimethylaminopropyl) carbodiimide hydrochloride (EDC.HCl), ninhydrin, Sephadex G-50 and acetic acid-d (99.9 atom \%D) were obtained from Sigma-Aldrich (UK). Deuterium oxide (99.9 atom $\%$ D) was purchased from Cambridge Isotope Lab. Inc. (USA), Phosal® $53 \mathrm{MCT}$ and Lutrol® micro 68 were supplied by Lipoid GmbH (Germany) and BASF Group (Ludwigshafen, Germany), respectively. Acetone, water (HPLC grade) and acetic acid glacial (analytical reagent) were purchased from Fisher Scientific (United Kingdom). Deionized water was prepared in-house (PURELAB, ELGA, UK).

\subsection{Synthesis of stearic acid-chitosan (CSO-SA)}

Chitosan oligomer (CSO) was conjugated by the reaction of the carboxyl groups of stearic acid in the presence of EDC. $\mathrm{HCl}$ with the free amino groups of chitosan oligomer 
(Fig.1), using an established method with minor modifications [25,26]. CSO (1 g) was dissolved in $120 \mathrm{~mL}$ of deionized water with magnetic stirring for $2 \mathrm{~h}$ at $80^{\circ} \mathrm{C}$. Meanwhile, $0.5 \mathrm{~g}$ stearic acid (SA) was dissolved in ethanol $(80 \mathrm{~mL})$ and heated at $60^{\circ} \mathrm{C}$, with stirring. SA solutions were activated by EDC.HCl (1:5 molar ratio) and stirred for $2 \mathrm{~h}$ at $60^{\circ} \mathrm{C}$. The solutions of SA were then added using a syringe with needle (BD Micro Lance $^{\mathrm{TM}} 3$, Spain) into the CSO solution with continuous stirring for $6 \mathrm{~h}$.

The product was evaporated under vacuum (Buchi Rotary evaporator, Buchi, Switzerland) at $70^{\circ} \mathrm{C}$ to reduce the volume. Unreacted $\mathrm{EDC} . \mathrm{HCl}$ and SA were removed by dialysis (Mwt cut-off $1000 \mathrm{Da}$, Spectrum Laboratories, USA) for 2 days, then the product precipitated using $300 \mathrm{~mL}$ of acetone and filtered using filter paper (Fisherbrand QL100, Fisher Scientific, UK). This precipitation/filtration step was repeated three times. Samples were stored in a desiccator for further analysis.

\subsubsection{Characterization of chitosan oligomer-stearic acid using Fourier Transform Infrared Spectroscopy (FTIR)}

Samples of CSO-SA, CSO and SA were analysed using FTIR to confirm the presence of the SA group in the CSO chain. Samples were analysed with 4 scans from 660 to $4000 \mathrm{~cm}^{-1}$ using PerkinElmer Spectrum100 FTIR (PerkinElmer, UK). The spectrum of CSO-SA was then compared to those of pure CSO and SA.

\subsubsection{Characterization of chitosan oligomer-stearic acid using ${ }^{1} \mathrm{H}$ NMR}

In order to confirm the presence of the fatty acid chain in the chitosan conjugate, samples were characterised using nuclear magnetic resonance spectroscopy (NMR). 5 $\mathrm{mg}$ of CSO, CSO-SA and SA was dissolved in $1 \mathrm{~mL}$ of deuterium oxide $\left(\mathrm{D}_{2} \mathrm{O}\right)$ with the addition of one drop of acetic acid- $\mathrm{d}_{4}$ in order to dissolve the product. The ${ }^{1} \mathrm{H}$ NMR spectra were obtained using a NMR Bruker Avance 500 spectrometer (Bruker Instruments, USA). 


\subsubsection{Determination of amine group substitution using ninhydrin assay}

The amount of chitosan conjugated with stearic acid was determined using ninhydrin as a reagent to react with the primary and secondary amino groups in the conjugated product [27]. The percent of free amino groups present in the CSO-SA conjugate was determined using the ninhydrin assay, by assuming the D-glucosamine slope has $100 \%$ amine groups, and the CSO and CSO-SA were then identified by comparing each slope. Serial dilutions of D-glucosamine (stock solution: $500 \mu \mathrm{g} / \mathrm{mL}$ ), CSO and CSO-SA (stock solution: $2000 \mu \mathrm{g} / \mathrm{mL}$ ) were prepared in $0.2 \%$ acetic acid solution. The working solutions for CSO and CSO-SA were 100, 60, 40 and $20 \mu \mathrm{g} / \mathrm{mL}$ and for D-glucosamine 25, 20, 15, 10, $5 \mu \mathrm{g} / \mathrm{mL}$. To prepare the ninhydrin solution, 0.35 $\mathrm{g}$ of ninhydrin was dissolved in $100 \mathrm{~mL}$ of ethanol.

To start the reaction, $0.5 \mathrm{~mL}$ of CSO or CSO-SA solutions, $0.5 \mathrm{~mL}$ of $4 \mathrm{M}$ acetate buffer ( $\mathrm{pH} 5.5$ ) and $2 \mathrm{~mL}$ of ninhydrin solution were combined and heated at $90^{\circ} \mathrm{C}$ in a water bath with stirring for $15 \mathrm{~min}$, then cooled to room temperature. The solution was then made up to $10 \mathrm{~mL}$ with ethanol. The absorbance was measured at $570 \mathrm{~nm}$ using Agilent Cary 100 UV-Vis Spectroscopy (Agilent Technologies UK Ltd., Berkshire, UK). The amounts of free amine groups in CSO and CSO-SA samples were assigned by comparing the slopes using linear regression from D-glucosamine where the absorbance (y) for each sample was plotted as a function of concentration (x).

\subsection{Preparation of dutasteride-loaded nanostructured lipid carriers (DST- NLCs)}

DST-NLCs were prepared by the melt-dispersion ultrasonication method [28-30]. Dutasteride (5 mg), stearic acid and Phosal® $53 \mathrm{MCT}$ were weighed into a glass vial. Lutrol@ micro 68 was added into another glass vial with water $(10 \mathrm{~mL})$. Both glass vials were heated separately at $80-90^{\circ} \mathrm{C}$ in a water bath. When the drug completely dissolved in the liquid lipid (by magnetic stirring), the aqueous solution was added into the oilphase solution. The mixture was homogenized using an IKA Ultra Turrax T25 (IKA Werke, Germany) at 19,000 rpm for $10 \mathrm{~min}$. The hot solution was further processed using a probe-type sonicator (MSE Soniprep 150, MSE, UK) at $18 \mathrm{~W}$, for $5 \mathrm{~min}$. $2 \mathrm{~mL}$ 
of hot dispersion was syringed (needle: 25 gauge, 5/8th inch) into $10 \mathrm{~mL}$ of cold water $\left(4-8^{\circ} \mathrm{C}\right)$ and stirred for $10 \mathrm{~min}$ to obtain nanoparticles. The formulation was stored at 4$8^{\circ} \mathrm{C}$ before being characterised. The weight of dutasteride was $5 \mathrm{mg}$, and $10 \mathrm{~mL}$ of water was used for all formulations.

\subsubsection{Experimental design of preparation of DST-NLCs using $2^{3}$ full factorial design}

The amount of solid lipid and surfactant used to prepare DST-NLCs was varied to obtain the smallest mean particle size, narrowest size distribution, and highest entrapment efficiency and drug loading. This was achieved with a $2^{3}$ full factorial design, Design Expert 6.0.8 Software (Stat-Ease, USA). The three factors evaluated were: the content of stearic acid $(A)$, Lutrol ${ }^{\circledR}$ micro $68(B)$ and Phosal ${ }^{\circledR} 53$ MCT $(C)$ (Table 1).

A factorial design was used to obtain maximum information, such as the interaction between the factors, whilst minimising the number of experiments [31]. The design required, in total, 8 preparations. The experiments were repeated three times to calculate the experimental error.

\subsubsection{Preparation of DST-NLCs coated with chitosan oligomer (CSO) and stearic acid-chitosan (CSO-SA)}

The optimised DST-NLC preparation was chosen based on statistical analysis. The formulation was scaled up from $100 \mathrm{mg}$ to $300 \mathrm{mg}$ of stearic acid to allow use of the desired concentration of dutasteride (approximately $0.3 \mathrm{mg} / \mathrm{mL}$ ). Quantities of other materials (dutasteride, Phosal® 53 MCT and Lutrol ${ }^{\circledR}$ micro 68) were up-scaled using the same ratio, with water kept constant at $10 \mathrm{~mL}$. The amount of dutasteride was optimised between 15 and $20 \mathrm{mg}$. CSO-SA (5 or $10 \%$ of solid lipid content) and CSO (5\% of solid lipid content) were dissolved in acidified water $(0.2 \%$ acetic acid in deionized water). $250 \mu \mathrm{L}$ of the solution was added, using a syringe (needle: 25 gauge, 5/8th inch), into $5 \mathrm{~mL}$ of DST-NLCs with constant stirring for $10 \mathrm{~min}$. 


\subsection{Characterization of DST-NLCs, uncoated and coated with CSO-SA or CSO}

\subsubsection{Measurement of particle size distribution, zeta potential and determination of nanoparticle morphology}

The size distribution and zeta potential of nanoparticles were obtained as $Z_{\mathrm{Ave}}$ hydrodynamic diameter, polydispersity index (PDI) and zeta potential ( $\xi$ ) using a Zetasizer Nano ZS (Malvern Instruments, UK) after 1 day, at $25^{\circ} \mathrm{C}$. Formulations were prepared with deionized water $(\mathrm{pH} 5.6)$ and used without further dilution. $1 \mathrm{~mL}$ of the sample was pipetted directly into the zeta potential DTS1070 folded capillary cell (Malvern, UK) without dilution. Measurements were performed 3 times, and mean values were taken. Zeta potential was calculated from electrophoretic mobility using the Helmholtz-Smoluchowski equation by the Malvern data analysis software..

The morphology of the nanoparticles was determined using transmission electron microscopy (TEM; Philips/FEI CM120 Bio Twin, FEI Netherlands). Samples were placed on copper grids for viewing and excess droplets were wicked away with filter paper [32]. After $2 \mathrm{~min}$, a drop of $1 \%$ phosphotungstic acid was placed onto the copper grid for negative staining. The grid was dried at room temperature and observed using TEM.

\subsubsection{Entrapment efficiency and drug loading}

Entrapment efficiency and drug loading were calculated as described previously [33], with modification. Entrapment efficiency and drug loading were determined using Sephadex ${ }^{\circledR}$ gel G-50 as a mini column. $5 \mathrm{~mL}$ of gel was packed in a $5 \mathrm{~mL}$ syringe, placed in a centrifuge tube (size of $50 \mathrm{~mL}$ ) and centrifuged at $1000 \mathrm{rpm}$ (angle rotor 19776-H, at $104 \mathrm{x} g$ ) for $10 \mathrm{~s}$ in a refrigerated centrifuge (Sigma Laborzentrifugen, Germany) at $20^{\circ} \mathrm{C}$ to remove excess water. Then, $0.5 \mathrm{~mL}$ DST-NLC preparation was pipetted in the middle of the column and separated by column chromatography at 1000 rpm for $5 \mathrm{~min}$. The column was washed with $0.5 \mathrm{~mL}$ deionized water at $1000 \mathrm{rpm}$ for a further $5 \mathrm{~min}$. The collected sample, dutasteride entrapped in NLCs, was diluted with ethanol in a $10 \mathrm{~mL}$ volumetric flask and sonicated for $10 \mathrm{~min}$ to dissolve the particles 
before filtration using a $0.22 \mu \mathrm{m}$ pore size syringe filter (Merck Millipore, Ireland). Unentrapped dutasteride was retained in the Sephadex G-50 gel. The ethanolic solution was assayed using a validated HPLC method to determine the total and entrapped dutasteride in the DST-NLCs.

High performance liquid chromatography (HPLC) with UV/Vis detector (Agilent 1100 Series, USA) at wavelength $241 \mathrm{~nm}$ was used to quantify dutasteride in preparations. The analytical column, Synergi ${ }^{\mathrm{TM}} 4 \mu \mathrm{m}$ Polar-RP $80 \AA$ A, 250 x $4.6 \mathrm{~mm}$ was selected as the stationary phase. Separation was carried out using a mobile phase 70:30 (by volume) of acetonitrile and $0.1 \%$ trifluroacetic acid (TFA) in HPLC grade water. The injection volume used was $30 \mu \mathrm{L}$ at $1 \mathrm{~mL} / \mathrm{min}$ flowrate.

Encapsulation efficiency was calculated from the amount of entrapped $\left(n_{1}\right)$ and total dutasteride in the preparation $\left(n_{2}\right)$ (Equation 1). Dutasteride loading was calculated using Equation 2.

$$
\text { Entrapment efficiency }(\%)=\frac{n_{1}}{n_{2}} \times 100
$$

\section{Equation 1}

where;

$n_{1}=$ concentration of entrapped dutasteride in DST-NLCs

$n_{2}=$ total concentration of dutasteride in DST-NLCs

$$
\text { Drug loading }(\%)=\frac{C_{1}}{C_{0}} \times 100
$$

where;

$$
\begin{aligned}
& C_{1}=\text { total weight of entrapped dutasteride in DST-NLCs } \\
& C_{0}=\text { total weight of solid lipid, surfactant and dutasteride in DST-NLCs }
\end{aligned}
$$

\subsubsection{Stability study}

The stability of DST-NLCs was investigated to explore potential changes in the size distribution and surface charge with time. Each formulation was stored in a refrigerator 
at $4-8^{\circ} \mathrm{C}$ and at $25^{\circ} \mathrm{C}$ (incubator). Particle size distribution and zeta potential were compared at day 1,30 and 60 .

\subsection{In vitro drug release}

In vitro release was studied using a Franz diffusion cell (PermeGear, USA). A $0.45 \mu \mathrm{m}$ HA nitrocellulose membrane (MFTM Membrane Filters, Merck Millipore, Ireland) was mounted in the Franz diffusion cell (surface area $=0.64 \mathrm{~cm}^{2}$ ) maintained at $37^{\circ} \mathrm{C}$ and stirred using a magnetic stirrer (600 rpm). Due to the limited solubility of dutasteride in phosphate-buffered saline (PBS), 2\% sodium dodecyl sulphate (SDS) was added. DSTNLCs, with or without chitosan $(250 \mu \mathrm{L})$, were pipetted in the donor chamber and sampling $(200 \mu \mathrm{L})$ was done at $0,0.25,0.5,1,2,3,6,8,12,24,30$ and $36 \mathrm{~h}$ from the receptor chamber, replaced with $200 \mu \mathrm{L}$ fresh buffer. Samples were injected into the HPLC to determine drug released.

\subsection{In vitro permeation}

An in vitro permeation study was conducted to quantify the amount of drug present in the skin and potential systemic exposure. In order to mimic topical application of the formulation, in vitro permeation was performed using a vertical Franz diffusion cell (PermeGear, USA). Pig ears were obtained from a local slaughterhouse (Farnborough, UK) from a freshly slaughtered pig (used for food consumption). The ears were washed with deionized water and hairs were trimmed carefully with scissors. The pig ear skin was excised using a scalpel and forceps and the subcutaneous tissue was removed. The average thickness of the skin was $\sim 0.5 \mathrm{~mm}$. The skin was cut and frozen $\left(-20^{\circ} \mathrm{C}\right)$ for future use.

The diffusion surface area of the Franz cell was $0.64 \mathrm{~cm}^{2}$. The receptor chamber was filled with $5 \mathrm{~mL}$ of PBS (pH 7.4) with $2 \%$ SDS and $0.02 \%$ sodium azide and maintained at $37^{\circ} \mathrm{C}$ whilst being stirred using a magnetic stirrer. The skin was mounted between the donor and receptor chambers and allowed to equilibrate for 1 h. $250 \mu \mathrm{L}$ of DST-NLCs formulation, with or without chitosan, was pipetted in the donor chamber. 
$200 \mu \mathrm{L}$ samples were withdrawn at $0,0.25,0.5,1,2,3,6,8,12,24,30,36$ and $48 \mathrm{~h}$, and $200 \mu \mathrm{L}$ fresh buffer added to the receptor chamber. Nanoparticle formulations were compared to ethanolic solutions of dutasteride $(0.29 \mathrm{mg} / \mathrm{mL}$ in $70 \%$ ethanol). After 48 $\mathrm{h}$, the stratum corneum was removed using a tape stripping method. The epidermis/dermis was chopped into small pieces using a scalpel and stirred for $24 \mathrm{~h}$ with ethanol and sonicated for $1 \mathrm{~h}$. The solution was filtered and injected into the HPLC for quantification of the drug which permeated in the skin.

\subsection{In vitro cytotoxicity study on hair follicle dermal papilla cells}

In order to determine the maximum non-toxic concentration (EC90) of unencapsulated and encapsulated dutasteride in nanoparticles, MTT assays on normal hair follicle dermal papilla cells were undertaken. Human hair follicle dermal papilla cells (HFDPCs) (Promo- Cell, Germany) were grown in HFDPCs growth medium (PromoCell, Germany) containing $100 \mathrm{IU} / \mathrm{ml}$ penicillin/streptomycin (Gibco-BRL, USA) and $2.5 \mu \mathrm{g} / \mathrm{ml}$ of amphotericin B (Sigma-Aldrich, UK) in a humidified 95\% atmosphere with $5 \% \mathrm{CO}_{2}$ at $37^{\circ} \mathrm{C}$. Cultured HFDPCs from passage 4 were seeded $\left(3.75 \times 10^{4}\right.$ per $\mathrm{mL}$ ) into 96-well plate (Nunc, Wiesbaden, Germany) and grown to a confluence of 60$70 \%$ for $24 \mathrm{~h}$. The MTT assay was conducted for 5 days with dutasteride alone (dutasteride alone was dissolved in DMSO at $100 \mathrm{mM}$ and serial dilutions were prepared from 100 to $1.6 \mu \mathrm{M}$ ), dutasteride in the nanoparticles coated or uncoated with CSO-SA $(12.5-100 \mu \mathrm{M})$ and empty NLCs coated and uncoated with CSO-SA (at the same concentration as DST-NLCs and DST-NLCs CSO-SA). MTT (5 mg/mL) was added to each well, and cells were incubated for $4 \mathrm{~h}$ at $37^{\circ} \mathrm{C}$. The supernatant was then removed, and $100 \mu \mathrm{L}$ of dimethylsulfoxide was added to dissolve formazan products. Absorbance was determined spectrophotometrically at $570 \mathrm{~nm}$ using microplate reader (SpectraMax®M2e, Molecular Devices, USA). Results were expressed as percentages of untreated controls in four cultures. Reported values represent means \pm SEM. 


\subsection{Statistical analysis}

All data were analysed either using a t-test or one-way ANOVA and Tukey's post-hoc test, using IBM SPSS Statistic 22, except data from the experimental design for the model (formulations) which were analysed using Design Expert 6.0.8 Software (StatEase, USA). A $p$-value of less than 0.05 was considered significant.

\subsection{RESULTS AND DISCUSSION}

\subsection{Synthesis and characterization of CSO-SA}

\subsection{1 ${ }^{1} \mathrm{H}$ NMR and FTIR}

Formation of the CSO-SA conjugate was determined using FTIR and ${ }^{1} \mathrm{H}$ NMR. The IR spectrum of CSO-SA showed two peaks at around 1636 and $1584 \mathrm{~cm}^{-1}$ corresponding to the N-stearoyl (amide bond) (Fig. 2a). The increase of the $\mathrm{C}-\mathrm{H}$ absorption around $\sim 2855 \mathrm{~cm}^{-1}$ indicated the presence of the stearoyl chain. The chemical shifts shown at 1.0 - $1.1 \mathrm{ppm}$ in the NMR spectrum represent protons from $\mathrm{CH}_{3}$ of stearic acid whereas the peaks at $1.13-1.15$ ppm correspond to protons of $\mathrm{CH}_{2}$ in the acyl chain (Fig. 2b). This finding agrees with previous studies [34,35]. The remaining peaks are due to hydrogen from the chitosan oligomer, indicating that stearic acid was conjugated to the chitosan oligomer.

\subsubsection{Degree of substitution determined by ninhydrin assay}

Based on the ninhydrin assay, the slopes for D-glucosamine and chitosan oligomer (CSO) and CSO-SA were 0.0676, 0.0126 and 0.0093, respectively. The number of amine groups on the chitosan oligomer was found to decrease due to the substitution of stearic acid. By comparing the slope from D-glucosamine and CSO; the percent degree of substitution (\%DS) of CSO-SA was calculated to be $6.0 \%$. 


\subsection{Preparation, optimization and characterization of DST-NLCs coated and uncoated with CSO-SA/CSO}

\subsubsection{Factorial design results on particle size distribution of DST-NLCs}

DST-NLCs were prepared according to a design of experiments. The main independent factors that might influence the particle size distribution were the contents of stearic acid, Lutrol ${ }^{\circledR}$ F68 and Phosal ${ }^{\circledR} 53$ MCT. All of the formulations gave mean size larger than $100 \mathrm{~nm}$ (Fig. 3).

Experimental design was employed to find the best model that relates the ratio of solid lipid and surfactant to mean particle size and PDI (a measure of the width of the size distribution). At day 1, there was no significance model term for the hydrodynamic diameter results $(p>0.05)$, suggesting high stability of the particles for the quantities of materials used. To obtain optimised, stable particles, the NLCs were stored at $4-8^{\circ} \mathrm{C}$ for 14 days (Fig. 3), revealing a significant difference in the model term for the hydrodynamic diameter at day $14(p<0.05)$.

From the modelling at day 14, the 'Predicted R-Squared' (0.8058) was in reasonable agreement with the 'Adjustment R-Squared' (0.9150). Table 2 shows the results of ANOVA on hydrodynamic diameter at day 14, indicating that some formulations were unstable, with increased hydrodynamic diameters after two weeks. The mathematical modelling of DST-NLCs on hydrodynamic diameter followed Equation 3 (coded value at day 14):

\section{Hydrodynamic diameter $(\mathrm{nm})=344.60-73.35 * A$}

$$
+31.10 * B-78.90 * A * B
$$

Equation 3

Where;

$A-$ Stearic acid

$B$ - Lutrol ${ }^{\circledR}$ micro 68

C-Phosal® 53 MCT 
Fig. 4a shows the interaction between stearic acid $(A)$ and Lutrol® micro $68(B)$ on hydrodynamic diameter. $100 \mathrm{mg}$ stearic acid, $50 \mathrm{mg}$ Lutrol ${ }^{\circledR}$ micro 68 and 25 or 50 mg Phosal® 53 MCT produced the smallest particles (S4 and S8), having a mean diameter of $223.5 \mathrm{~nm}$. Increasing surfactant content stabilized the nanoparticles, with a reduction in mean size. Hydrophilic-Lipophilic Balance (HLB) is a major consideration in making stable emulsions. In this study, Lutrol $®$ F68 has a high HLB value (>24) and soy phosphatidycholine (53\% in Phosal ${ }^{\circledR} 53$ MCT) has a low HLB value (4). Using a mix of emulsifiers can stabilize the emulsion in terms of coalescence rate [36].

Model $A, C, A B$ and $A C$ were significantly different ( $p<0.05$ ) on PDI at day 14 (Table 3). 'Predicted R-Squared' (0.9761) from the model was in reasonable agreement with the 'Adjustment R-Squared' (0.9948). Equation 4 shows the model for PDI at day 14 (in coded value).

$$
\begin{aligned}
(\mathrm{PDI})= & 0.23-0.048 * A+4.750 \times 10^{-3 *} B+0.042 * C \\
& -0.038 * A * B-0.015 * A * C
\end{aligned}
$$

\section{Equation 4}

where;

$$
\begin{aligned}
& A-\text { Stearic acid } \\
& B \text { - Lutrol }{ }^{\circledR} \text { micro } 68 \\
& C \text { - Phosal }{ }^{\circledR} 53 \text { MCT }
\end{aligned}
$$

Figs. $4 \mathrm{~b}$ and $4 \mathrm{c}$ show a 3D-surface graph of the interaction between stearic acid (A), Lutrol ${ }^{\circledR}$ micro F68 (B) and stearic acid with Phosal® 53 MCT (C). $100 \mathrm{mg}$ stearic acid, $50 \mathrm{mg}$ Lutrol ${ }^{\circledR}$ micro 68 and $25 \mathrm{mg}$ Phosal ${ }^{\circledR} 53$ MCT (Formulation S4), produced NLCs with a narrow particle size distribution (PDI=0.123). When the amount of surfactant was increased, PDI decreased with a mondispersed size distribution. It has been shown in the previous research that by increasing the surfactant, the particle size was decreased at certain concentration [36]. At low concentrations of surfactant, aggregation is accelerated where the fraction of particle surface area which is coated remains small. At higher surfactant concentration, all the agglomerated particles are coated and the particle size is reduced [36]. This allows ease of dispersion, reduced aggregation and hence a reduction in PDI. 


\subsubsection{Factorial design results for surface charge}

Fig. 5 shows all particles had negative charge due to the presence of the stearic acid. There was no significant difference (ANOVA, $p>0.05$ ) on the model for zeta potential at day 1 or day 14 . Based on the results for hydrodynamic diameter and PDI, formulation S4 and S8 were chosen and further analysed using a t-test, which revealed no significant difference $(p>0.05)$ for zeta potential between S4 and S8.

\subsubsection{Factorial design results for entrapment efficiency and drug loading}

The entrapment efficiency (\%EE) for all formulations was greater than $60 \%$ (Table 4). Table 5 shows ANOVA results for entrapment efficiency. Based on the results (Fig. 6), model $A$ and $A B$ were significantly different $(p<0.05)$. Based on the model, $100 \mathrm{mg}$ stearic acid, $50 \mathrm{mg}$ Lutrol ${ }^{\circledR}$ micro 68 and 25 or $50 \mathrm{mg}$ Phosal® 53 MCT produced highest entrapment efficiency (95.1\%). The content of stearic acid and the interaction between stearic acid and Lutrol® micro 68 significantly impacted EE\% ( $p<0.05)$. However, there was no significant impact on drug loading $(p>0.05)$, with the mean drug loading for all formulations being in the range 2 to $4.40 \%$.

The mathematical modelling of entrapment efficiency for DST-NLCs followed Equation 5 (coded value):

$$
\mathrm{EE} \%=82.14+10.24 * A-2.61 * B+5.29 * A * B
$$

\section{Equation 5}

Where;

$$
\begin{aligned}
& A-\text { stearic acid } \\
& B \text { - Lutrol }{ }^{\circledR} \text { micro } 68 \\
& C \text { - Phosal }{ }^{\circledR} 53 \text { MCT }
\end{aligned}
$$

\subsubsection{Stability of DST-NLCs on storage}

Hydrodynamic diameter and particle size distribution were studied on day 1 and 14 (Fig. 3). There were no significant differences $(p>0.05)$ in the hydrodynamic diameter at day 1. At day 14, some formulations demonstrated an increase in mean size, 
especially S3 and S7. This may be due to the amount of surfactant present being insufficient to stabilize the formulations. The results indicate that the ratio of contents in S4 (100 mg stearic acid, $50 \mathrm{mg}$ Lutrol ${ }^{\circledR}$ micro 68 and $25 \mathrm{mg}$ Phosal® 53 MCT) and S8 (100 mg stearic acid, $50 \mathrm{mg}$ Lutrol ${ }^{\circledR}$ micro 68 and $50 \mathrm{mg}$ Phosal ${ }^{\circledR} 53$ MCT) gave the smallest hydrodynamic diameter and PDI at day 1 and day 14 . There was no significant difference $(p>0.05)$ between $\mathrm{S} 4$ and S8 at day 1, and 14 with respect to hydrodynamic diameter and PDI. Consequently, Formulation S4 was selected for the subsequent investigations.

\subsubsection{Effect of scale-up of the DST-NLCs preparation}

Formulation S4 was selected, as indicated above, and production quantities scaled up $3 x$. Mean hydrodynamic diameter and PDI were not significantly altered ( $p>0.05$; data not shown). Then, the amount of dutasteride was varied and $17.5 \mathrm{mg}$ dutasteride was found to be the optimal content, giving highest entrapment efficiency $(97.8 \pm 0.68 \%)$. When drug content was increased to $20 \mathrm{mg}$, entrapment efficiency decreased to $90.1 \pm$ $1.07 \%$, indicating the limitation of the amount of drug that can be loaded in this carrier system, as reported previously [37]. Furthermore, there was no significant difference $(p>0.05)$ in drug loading $(3.49 \pm 0.10 \%)$.

\subsubsection{Particle size distribution of DST-NLCs uncoated and coated with CSO-SA and CSO}

The nanoparticles were coated with CSO and CSO-SA using a physical adsorption method. There was a significant increase in mean size following coating $(p<0.05)$, from $187.6 \pm 7.0 \mathrm{~nm}$ to $220.1 \pm 11.9 \mathrm{~nm}$ and $230.1 \pm 8.2 \mathrm{~nm}$ when coated with 5 and $10 \%$ CSO-SA, respectively. Coating with 5\% CSO, the size was $208.4 \pm 1.6 \mathrm{~nm}(p>0.05)$. There was not significant difference $(p>0.05)$ in PDI for the preparations, with mean PDI $<0.2$, indicating all had narrow size distributions.

Based on the TEM images, uncoated DST-NLCs and those coated with CSO/CSO-SA were spherical (Fig. 7) and in the size range approximately $200-250 \mathrm{~nm}$. There was some 
suggestion of aggregation for DST-NLCs coated with 10\% CSO-SA (Fig. 7D), probably due to the higher concentration of CSO-SA.

\subsubsection{Zeta potential of DST-NLCs before and after coating}

The zeta potential of DST-NLCs changed from negative to positive on coating $(p<0.05)$, with CSO-SA or CSO adsorbed to negatively-charged DST-NLCs, producing positively-charged nanoparticles. Zeta potential value was increased from $+26.0 \pm 1.1$ $\mathrm{mV}$ to $+30.0 \pm 1.2 \mathrm{mV}$ for $5 \%$ to $10 \%$ of CSO-SA $(p<0.05)$. The charge was higher for DST-NLCs coated with 5\% CSO-SA than with 5\% CSO $(21.7 \pm 2.1 \mathrm{mV})(p<0.05)$. These findings indicated good interaction between DST-NLCs and CSO-SA, stabilizing the nanoparticles. This may result in part, from CSO-SA having some amphiphilic properties, as reported by $\mathrm{Hu}$ et al. [35] who produced stable doxorubicin-loaded polymeric micelles of a chitosan oligosaccharide-stearic acid conjugate. Moreover, the highly positively-charged CSO-SA will be electrostatically attracted to the negativelycharged surface of DST-NLCs. Previous studies [24,38-41] have demonstrated the electrostatic interaction between positively-charged chitosan and negatively-charged nanoparticles.

\subsubsection{Stability of DST-NLCs uncoated, and coated with CSO-SA and CSO}

DST-NLCs coated with $10 \% \mathrm{CSO}-\mathrm{SA}$ and $5 \% \mathrm{CSO}$ aggregated when stored at $25^{\circ} \mathrm{C}$ (Table 6). However, uncoated DST-NLCs and those coated with 5\% CSO-SA and 10\% CSO-SA were stable at $4-8^{\circ} \mathrm{C}$ over a period of 60 days. DST-NLCs coated with $5 \%$ CSO-SA and 10\% CSO-SA, had unchanged mean particle size and PDI at day 1, 30 and 60 ( $p<0.05)$. However, DST-NLCs coated with 5\% CSO demonstrated physical instability, with aggregation even when stored at $4-8^{\circ} \mathrm{C}$ (day 30 ), possibly due to differences in the physical properties of the CSO compared to CSO-SA.

When uncoated DST-NLCs and those coated with 5\% CSO-SA were stored at $25^{\circ} \mathrm{C}$, the mean particle size increased by 2 -fold compared to samples stored at $4-8^{\circ} \mathrm{C}$. NLCs coated with $5 \% \mathrm{CSO}$, stored at $25^{\circ}$ were aggregated at day 30 . This might be due to the changes in polymer behaviour at different temperatures [42]. Increasing the 
concentration of CSO-SA from $5 \%$ to $10 \%$ produced aggregation, possibly resulting from excess CSO-SA in the formulation, not associated with the NLC coating. The data indicate NLCs coated with chitosan without conjugation were relatively unstable. Having the hydrophobic chain (steroyl chain) in the chitosan-conjugate may enhance the stability of the nanoparticles, when the CSO-SA (at an appropriate concentration) was employed as a coating material.

\subsubsection{In vitro release from uncoated and coated DST-NLCs}

All nanoparticle preparations showed rapid release over the first $12 \mathrm{~h}$ (Fig. 8), with uncoated DST-NLCs exhibiting fastest release $(p<0.05)$. There was no significant difference $(p>0.05)$ between DST-NLCs coated with 5\% and 10\% CSO-SA, both having approximately $60 \%$ drug release at $36 \mathrm{~h}$.

DST-NLCs without coating showed $72 \%$ release at $24 \mathrm{~h}$. DST-NLCs coated with CSOSA had a lower drug release due to the presence of the polymer in the outer regions of the particles. In contrast, DST-NLCs coated with 5\% CSO (no conjugation) showed a slower release where $40.7 \pm 5.1 \%$ of drug has been released at $36 \mathrm{~h}$. Dutasteride in $70 \%$ ethanol (as control) showed only $32.6 \pm 10.7 \%$ release at $36 \mathrm{~h}$ into the receptor media, probably due to the limited solubility of dutasteride in the receptor media. No precipitation was observed in the donor chamber after the experiment. The result was similar to that described previously whereby diphencyprone (slightly soluble in water) was released more slowly from ethanolic solution than from NLCs or a nanoemulsion formulation [43].

\subsubsection{In vitro permeation}

In vitro permeation studies using pig ear skin were conducted to mimic human skin. The follicular structure of pig ear skin is very similar to humans where their infundibula extend deep in the dermis, as in humans [44]. For all formulations, no dutasteride was detectable by HPLC in the receptor chamber ( $\mathrm{LOQ}=3 \mu \mathrm{g} / \mathrm{mL}$ ). Considering, the 
amount of dutasteride present in the skin (Fig. 9), the highest permeation in the skin $\left(12.62 \pm 1.72 \mu \mathrm{g} / \mathrm{cm}^{2}\right)$ was found from the ethanol solution.

This result was in agreement with previous research, in that ethanol acts as a penetration enhancer in topical products [45]. There was a significant difference $(p<0.05)$ in the amount of dutasteride in the skin from ethanol and the hydrophobic drug-nanoparticle formulation. There were significant differences in the amount of dutasteride in the skin $(p<0.05)$ when DST-NLCs $\left(6.09 \pm 1.09 \mu \mathrm{g} / \mathrm{cm}^{2}\right)$ were coated with $5 \%$ CSO-SA $\left(2.82 \pm 0.40 \mu \mathrm{g} / \mathrm{cm}^{2}\right), 10 \%$ CSO-SA $\left(2.70 \pm 0.35 \mu \mathrm{g} / \mathrm{cm}^{2}\right)$ or CSO $\left(2.11 \pm 0.64 \mu \mathrm{g} / \mathrm{cm}^{2}\right)$. This result was similar to previous research [46] where they found benzophenone-3 loaded chitosan coated polymeric nanocapsules was less in the dermis and epidermis compared to uncoated with chitosan. These results could be discussed by the different surface charge between polysaccharide from chitosan and the epithelium as previously discussed for the ocular epithelium [47] and also the bioadhesive characteristic of chitosan [48]. Further experiments such as in vivo studies are required to confirm these formulation effects on permeation. In normal application, the same concentration of dutasteride will be applied on the scalp where the surface area will be much higher. Moreover, massaging of the scalp which will increase the total amount of the drug in the skin, since previous research has shown such massage resulted in deeper penetration of nanoparticles in the hair follicular region[11]. The small size of these DST-NLCs uncoated and coated with CSO-SA (200- $250 \mathrm{~nm})$ will ensure deep penetration into the hair follicle duct [11]. The different size of nanoparticles will affect the penetration depth [13]. Particles in the size range used in this study would be predicted to penetrate the upper part of follicle of terminal hair, and would likely penetrate deeper in the vellus hair follicles, especially on the balding site, where the hair is short, thin and fine. By contrast, application of ethanol-based formulations produces documented adverse reactions. The adverse reactions resulting from ethanol-use as a carrier (e.g. scalp dryness, irritation and burning, contact dermatitis [49]), should be avoided by using nanoparticle formulations. 


\subsubsection{In vitro cytotoxicity}

After 5 days of treatment with various concentrations of dutasteride (alone) and nanoparticles, there was a significant difference $(p<0.05)$ in cytotoxicity values $\left(\mathrm{IC}_{50}\right)$. Dutasteride alone (Fig. 10A) showed cytotoxicity at very low concentrations $\left(\mathrm{IC}_{50}=\right.$ $10.4 \pm 1.82 \mu \mathrm{M})$. Values of $\mathrm{IC}_{50}$ for DST-NLCs, coated and uncoated with CSO-SA (Fig. 10B) were higher; up to $59.3 \pm 13.1 \mu \mathrm{M}$ and $58.1 \pm 13.0 \mu \mathrm{M}$, respectively. For the maximum non-toxic concentration (MNTC, $\mathrm{EC}_{90}$ ), dutasteride without nanoparticles at $2.1 \pm 0.2 \mu \mathrm{M}$ killed $10 \%$ of normal human dermal papilla cells. Meanwhile, dutasteride in the nanoparticles either coated with CSO-SA $(53.6 \pm 8.3 \mu \mathrm{M})$ or uncoated $(38.1 \pm$ $13.1 \mu \mathrm{M}$ ) could be applied at a higher concentration compared to the dutasteride without nanoparticles. However, NLCs alone (without dutasteride) also showed cytotoxicity $\left(\mathrm{IC}_{50}=58.1 \pm 13.0 \mu \mathrm{M}\right)$ in a dose-dependent manner. The MNTC $\left(\mathrm{EC}_{90}\right)$ for NLCs uncoated and coated with CSO-SA was $42.3 \pm 12.4 \mu \mathrm{M}$ and $49.4 \pm 6.0 \mu \mathrm{M}$, respectively. There was no significant difference $(p<0.05)$ in MNTC between uncoated DST-NLCs and those coated with CSO-SA. This showed that when dutasteride was delivered using nanoparticles, it increased MNTC (EC90) of the drug approximately 20-fold, probably due to the slow release of the drug from the nanocarrier system. It is interesting to note that, NLCs (with no dutasteride) coated and uncoated with CSO-SA also proliferated the hair follicle dermal papilla cells at $25 \mathrm{uM}$ (comparable with the formulation containing dutasteride) when compared to the control. This shows that, stearic acid acts as a main component for the NLCs system and could itself promote hair growth. An efficacy study of the formulations on $5 \alpha$-reductase inhibition is on-going.

\subsection{CONCLUSION}

The stearic acid-chitosan conjugate was successfully prepared, as confirmed by ${ }^{1} \mathrm{NMR}$ and FTIR analysis. DST-NLCs produced good entrapment efficiency $(97.8 \pm 0.68 \%$ ) and drug loading $(3.49 \pm 0.10 \%)$, using $17.5 \mathrm{mg}$ of dutasteride in the scaled-up formulation. By adding CSO-SA to DST-NLCs, the mean hydrodynamic diameter and PDI were increased, and the NLCs had a high positive charge. DST-NLCs coated with $5 \%$ CSO showed good stability after 60 days. The release profile for DST-NLCs coated 
with CSO-SA indicated slow release over the first $12 \mathrm{~h}$. In the permeation study, no dutasteride was detected in the receptor chamber after $48 \mathrm{~h}$, indicating dutasteride has low permeability. An amount of $6.09 \pm 1.09 \mu \mathrm{g} / \mathrm{cm}^{2}$ and $2.82 \pm 0.40 \mu \mathrm{g} / \mathrm{cm}^{2}$ respectively, of dutasteride were found in the skin after $48 \mathrm{~h}$ of the permeation studies, indicating that DST-NLCs, uncoated and coated with 5\% CSO-SA would be a good carrier for dutasteride. By encapsulating the dutasteride in the NLC formulations the maximum non-toxic concentration was increased approximately 20-fold. Further work using celluptake studies is required to establish the ability of these, or related formulations to target hair follicle dermal papilla cells for promoting the hair growth. As a conclusion, dutasteride-loaded nanostructured lipid carriers coated with stearic acid-chitosan conjugate (CSO-SA), represent a promising strategy for topical delivery of dutasteride.

\section{Conflict of interest}

The authors declare there are no conflicts of interest.

\section{Acknowledgements}

The authors gratefully thank David McCarthy (UCL) for TEM images. We would like to acknowledge Universiti Teknologi Malaysia and the Ministry of Education for funding doctoral studies under non-academic PhD Scholarship.

\section{REFERENCES}

[1] M. Yassa, M. Saliou, Y. De Rycke, C. Hemery, M. Henni, J.M. Bachaud, N. Thiounn, J.M. Cosset, and P. Giraud, Male pattern baldness and the risk of prostate cancer., Ann. Oncol. 22 (2011) 1824-1827. doi:10.1093/annonc/mdq695.

[2] V.A. Randall and N.I. Botchkareva, The Biology of Hair Growth, First Edit, William Andrew Inc., 2009. doi:10.1016/B978-0-8155-1572-2.50006-3. 
[3] N. Hibberts, A. Howell, and V. Randall, Balding hair follicle dermal papilla cells contain higher levels of androgen receptors than those from non-balding scalp., $\mathrm{J}$ Endocrinol. 156 (1998) $59-65$. http://www.ncbi.nlm.nih.gov/pubmed/9496234.

[4] E. Olsen, M. Hordinsky, D. Whiting, D. Stough, S. Hobbs, M.L. Ellis, T. Wilson, and R.S. Rittmaster, The importance of dual $5 \alpha$-reductase inhibition in the treatment of male pattern hair loss: Results of a randomized placebo-controlled study of dutasteride versus finasteride, J. Am. Acad. Dermatol. 55 (2006) 10141023. doi:10.1016/j.jaad.2006.05.007.

[5] D.W. Russell and J.D. Wilson, Steroid 5alpha-Reductase: Two Genes / Two Enzymes, Annu. Rev. Biochem. 63 (1994) 25-61.

[6] H.C. Eun, O.S. Kwon, J.H. Yeon, H.S. Shin, B.Y. Kim, B.I. Ro, H.K. Cho, W.Y. Sim, B.L. Lew, W.-S. Lee, H.Y. Park, S.P. Hong, and J.H. Ji, Efficacy, safety, and tolerability of dutasteride $0.5 \mathrm{mg}$ once daily in male patients with male pattern hair loss: a randomized, double-blind, placebo-controlled, phase III study., J. Am. Acad. Dermatol. 63 (2010) 252-8. doi:10.1016/j.jaad.2009.09.018.

[7] A.K. Gupta and A. Charrette, The efficacy and safety of 5 $\alpha$-reductase inhibitors in androgenetic alopecia : a network meta-analysis and benefit - risk assessment of finasteride and dutasteride, J. Dermatolog. Treat. 25 (2014) 156-161. doi:10.3109/09546634.2013.813011.

[8] S. Gur, P.J. Kadowitz, and W.J. Hellstorm, Effects of 5-alpha reductase inhibitors on erectile function, sexual desire and ejaculation, Expert Opin. Drug Saf. 12 (2013) 81-90. doi:10.1517/14740338.2013.742885.

[9] N.H. Ansari, E. Anis, S.F.S. Firdaus, S. Wahab, and M.F.A.N. Mishra, Synthesis of Dutasteride Loaded Nanoemulsion, Int. J. Sci. Res. (2013) 85-87.

[10] T. Madheswaran, R. Baskaran, P. Sundaramoorthy, and B.K. Yoo, Enhanced skin permeation of $5 \alpha$-reductase inhibitors entrapped into surface-modified liquid 
crystalline nanoparticles, Arch. Pharm. Res. 38 (2015) 534-542. doi:10.1007/s12272-014-0464-8.

[11] J. Lademann, H. Richter, A. Teichmann, N. Otberg, U. Blume-Peytavi, J. Luengo, B. Weiss, U.F. Schaefer, C.-M. Lehr, R. Wepf, and W. Sterry, Nanoparticles - An efficient carrier for drug delivery into the hair follicles., Eur. J. Pharm. Biopharm. 66 (2007) 159-64. doi:10.1016/j.ejpb.2006.10.019.

[12] U. Blume-Peytavi, L. Massoudy, A. Patzelt, J. Lademann, E. Dietz, U. Rasulev, and N. Garcia, Follicular and percutaneous penetration pathways of topically applied minoxidil foam, Eur. J. Pharm. Biopharm. 76 (2010) 450-453. doi:10.1016/j.ejpb.2010.06.010.

[13] A. Patzelt, H. Richter, F. Knorr, U. Schäfer, C. Lehr, L. Dähne, W. Sterry, and J. Lademan, Selective follicular targeting by modification of the particle sizes, J. Control. Release. 150 (2011) 45-48. doi:10.1016/j.jconrel.2010.11.015.

[14] R.H. Muller, K. Mader, A. Lippacher, and V. Jenning., Solid-liquid (semi-solid) liquid particles and method of producing highly concentrated lipid particle dispersions, PCT/EP00/04565, 2000.

[15] R.H. Müller, A. Hommoss, J. Pardeike, and C. Schmidt, Lipid nanoparticles (NLC) as novel carrier for cosmetics - Special features \& state of commercialisation, SÖFW. 9 (2007) 40-46.

[16] J.S. Lucks and R.H. Müller, Medication Vehicles Made of Solid Lipid Particles (Solid Lipid Nanospheres SLN), 1991.

[17] X. Yang, H.Y. Lee, J. Kim, X. Yang, H.Y. Lee, and J. Kim, In vitro skin permeation of hinokitiol loaded in vesicles composed of behenyltrimethylammonium chloride and stearic acid, Drug Dev. Ind. Pharm. 36 (2010) 556-562. doi:10.3109/03639040903325578.

[18] K. Shimizu, R. Kondo, K. Sakai, Y. Shoyama, H. Sato, and T. Ueno, Steroid 
5alpha-reductase inhibitory activity and hair regrowth effects of an extract from Boehmeria nipononivea, Biosci Biotechnol Biochem. 64 (2000) 875-877.

[19] GlaxoSmithKline Inc., Clinical Pharmacological and Biopharmaceutics ReviewDutasteride (Code name:GI1987, North Carolina, 2001. doi:http://www.accessdata.fda.gov/drugsatfda_docs/nda/2001/21319_duagen_bi opharmr_p1.pdf.

[20] J. Pardeike, A. Hommoss, and R.H. Müller, Lipid nanoparticles (SLN, NLC) in cosmetic and pharmaceutical dermal products., Int. J. Pharm. 366 (2009) 17084. doi:10.1016/j.ijpharm.2008.10.003.

[21] A. Mittal, K. Schulze, T. Ebensen, S. Weissmann, S. Hansen, C. a. Guzmán, and C.-M. Lehr, Inverse micellar sugar glass (IMSG) nanoparticles for transfollicular vaccination, J. Control. Release. $206 \quad$ (2015) 140-152. doi:10.1016/j.jconrel.2015.03.017.

[22] H. Hamishehkar, S. Ghanbarzadeh, S. Sepehran, Y. Javadzadeh, Z.M. Adib, and M. Kouhsoltani, Histological assessment of follicular delivery of flutamide by solid lipid nanoparticles: potential tool for the treatment of androgenic alopecia, Drug Dev. Ind. Pharm. 9045 (2015) 1-8. doi:10.3109/03639045.2015.1062896.

[23] B. Bhushan, Biophysics of Human Hair, Springer Berlin Heidelberg, Berlin, Heidelberg, 2010. doi:10.1007/978-3-642-15901-5.

[24] D.M. Ridolfi, P.D. Marcato, G.Z. Justo, L. Cordi, D. Machado, and N. Durán, Chitosan-solid lipid nanoparticles as carriers for topical delivery of tretinoin., $\begin{array}{llllll}\text { Colloids } & \text { Surf. } & \text { B. } & \text { Biointerfaces. } & 93 & \text { (2012) }\end{array}$ doi:10.1016/j.colsurfb.2011.11.051.

[25] J.-P. Nam, S.-C. Park, T.-H. Kim, J.-Y. Jang, C. Choi, M.-K. Jang, and J.-W. Nah, Encapsulation of paclitaxel into lauric acid-O-carboxymethyl chitosantransferrin micelles for hydrophobic drug delivery and site-specific targeted delivery., Int. J. Pharm. 457 (2013) 124-135. doi:10.1016/j.ijpharm.2013.09.021. 
[26] H. Yuan, L. Lu, Y. Du, and F. Hu, Stearic Acid-g-chitosan Polymeric Micelle for Oral Drug Delivery : In Vitro Transport and In Vivo Absorption, Mol. Pharm. 8 (2010) 225-238.

[27] E. Curotto and F. Aros, Quantitative determination of chitosan and the percentage of free amine groups, Anal. Biochem. (1993) 240-241.

[28] S. Uprit, R. Kumar Sahu, A. Roy, and A. Pare, Preparation and characterization of minoxidil loaded nanostructured lipid carrier gel for effective treatment of alopecia., Saudi Pharm. J. SPJ Off. Publ. Saudi Pharm. Soc. 21 (2013) 379-85. doi:10.1016/j.jsps.2012.11.005.

[29] M.J. Gomes, S. Martins, D. Ferreira, M. a Segundo, and S. Reis, Lipid nanoparticles for topical and transdermal application for alopecia treatment: development, physicochemical characterization, and in vitro release and penetration studies., Int. J. Nanomedicine. 9 (2014) 1231-42. doi:10.2147/IJN.S45561.

[30] D. Patel, S. Dasgupta, S. Dey, Y.R. Ramani, S. Ray, and B. Mazumder, Nanostructured Lipid Carriers (NLC)-Based Gel for the Topical Delivery of Aceclofenac: Preparation, Characterization, and In Vivo Evaluation., Sci. Pharm. 80 (2012) 749-64. doi:10.3797/scipharm.1202-12.

[31] K. Dillen, J. Vandervoort, G. Van Den Mooter, L. Verheyden, and A. Ludwig, Factorial design, physicochemical characterisation and activity of ciprofloxacinPLGA nanoparticles, Int. J. Pharm. 275 (2004) 171-187. doi:10.1016/j.ijpharm.2004.01.033.

[32] Y.-T. Xie, Y.-Z. Du, H. Yuan, and F.-Q. Hu, Brain-targeting study of stearic acidgrafted chitosan micelle drug-delivery system., Int. J. Nanomedicine. 7 (2012) 3235-44. doi:10.2147/IJN.S32701.

[33] X. Gu, W. Zhang, J. Liu, J.P. Shaw, Y. Shen, Y. Xu, H. Lu, and Z. Wu, Preparation and characterization of a lovastatin-loaded protein-free 
nanostructured lipid carrier resembling high-density lipoprotein and evaluation of its targeting to foam cells., AAPS PharmSciTech. 12 (2011) 1200-8. doi:10.1208/s12249-011-9668-0.

[34] Q. Li, Y.-Z. Du, H. Yuan, X.-G. Zhang, J. Miao, F.-D. Cui, and F.-Q. Hu, Synthesis of lamivudine stearate and antiviral activity of stearic acid-g-chitosan oligosaccharide polymeric micelles delivery system., Eur. J. Pharm. Sci. 41 (2010) 498-507. doi:10.1016/j.ejps.2010.08.004.

[35] F.-Q. Hu, L.-N. Liu, Y.-Z. Du, and H. Yuan, Synthesis and antitumor activity of doxorubicin conjugated stearic acid-g-chitosan oligosaccharide polymeric micelles., $\quad$ Biomaterials. $\quad 30 \quad$ (2009) 6955-63. doi:10.1016/j.biomaterials.2009.09.008.

[36] T. Prozorov, G. Kataby, R. Prozorov, and a. Gedanken, Effect of surfactant concentration on the size of coated ferromagnetic nanoparticles, Thin Solid Films. 340 (1999) 189-193. doi:10.1016/S0040-6090(98)01400-X.

[37] N.N. Gaber, Y. Darwis, P. Kok-Khiang, and Y. Tze Fung Tan, Characterization of polymeric micelles for pulmonary delivery of beclomethasone dipropionate, $\mathrm{J}$ Nanosci Nanotechnol. 6 (2006) 3095-101.

[38] Q. Luo, J. Zhao, X. Zhang, and W. Pan, Nanostructured lipid carrier (NLC) coated with Chitosan Oligosaccharides and its potential use in ocular drug delivery system, Int. J. Pharm. 403 (2011) 185-191. doi:10.1016/j.ijpharm.2010.10.013.

[39] R. Nair, A.C.K. Kumar, V.K. Priya, C.M. Yadav, and P.Y. Raju, Formulation and evaluation of chitosan solid lipid nanoparticles of carbamazepine., Lipids Health Dis. 11 (2012) 72. doi:10.1186/1476-511X-11-72.

[40] P. Fonte, T. Nogueira, C. Gehm, D. Ferreira, and B. Sarmento, Chitosan-coated solid lipid nanoparticles enhance the oral absorption of insulin, Drug Deliv. Transl. Res. 1 (2011) 299-308. doi:10.1007/s13346-011-0023-5. 
[41] Y.-C. Kuo and C.-C. Wang, Cationic solid lipid nanoparticles with cholesterolmediated surface layer for transporting saquinavir to the brain., Biotechnol. Prog. 30 (2013) 198-206. doi:10.1002/btpr.1834.

[42] S. dos Santos, B. Edronho, T. Santos, and F.E. Antunes, Amphiphilic Molecules in Drug Delivery Systems, in: J. Coelho (Ed.), Adv. Predict. Prev. Pers. Med., Spinger, 2013: pp. 35-85. doi:10.1007/978-94-007-6010-3.

[43] I.A. Aljuffali, C.T. Sung, F.-M. Shen, C.-T. Huang, and J.-Y. Fang, Squarticles as a lipid nanocarrier for delivering diphencyprone and minoxidil to hair follicles and human dermal papilla cells., AAPS J. 16 (2014) 140-50. doi:10.1208/s12248-013-9550-y.

[44] U. Jacobi, M. Kaiser, R. Toll, S. Mangelsdorf, H. Audring, N. Otberg, W. Sterry, and J. Lademann, Porcine ear skin: an in vitro model for human skin., Skin Res. Technol. 13 (2007) 19-24. doi:10.1111/j.1600-0846.2006.00179.x.

[45] A.C. Williams and B.W. Barry, Penetration enhancers, Adv. Drug Deliv. Rev. 56 (2004) 603-618. doi:10.1016/j.addr.2003.10.025.

[46] N.M. Siqueira, R. V. Conti, K. Paese, R.C.R. Beck, A.R. Pohlmann, and S.S. Guterres, Innovative Sunscreen Formulation Based on Benzophenone-3-Loaded Chitosan-Coated Polymeric Nanocapsules, Skin Pharmacol. Physiol. 24 (2011) 166-174. doi:10.1159/000323273.

[47] A.M. De Campos, A. Sanchez, R. Gref, P. Calvo, and M.J. Alonsoa, The effect of a PEG versus a chitosan coating on the interaction of drug colloidal carriers with the ocular mucosa, Eur. J. Pharm. Sci. 20 (2003) 73-81.

[48] M. Rinaudo, Chitin and chitosan: Properties and applications, Prog. Polym. Sci. 31 (2006) 603-632. doi:10.1016/j.progpolymsci.2006.06.001.

[49] D.W. Lachenmeier, Safety evaluation of topical applications of ethanol on the skin and inside the oral cavity, J. Occup. Med. Saf. 16 (2008) 1-16. 
doi:10.1186/1745-6673-3-26. 
Table 1 Design of experiment for preparing dutasteride-loaded nanostructured lipid carrier (DST-NLCs) using a $2^{3}$ full factorial design

\begin{tabular}{cccc}
\hline Formulation & Stearic acid (mg) & $\begin{array}{c}\text { Lutrol® micro } \\
\mathbf{6 8}(\mathbf{m g})\end{array}$ & $\begin{array}{c}\text { Phosal® 53 MCT } \\
(\mathbf{m g})\end{array}$ \\
\hline S1 & $50(-1)$ & $25(-1)$ & $25(-1)$ \\
S2 & $100(+1)$ & $25(-1)$ & $25(-1)$ \\
S3 & $50(-1)$ & $50(+1)$ & $25(-1)$ \\
S4 & $100(+1)$ & $50(+1)$ & $25(-1)$ \\
S5 & $50(-1)$ & $25(-1)$ & $50(+1)$ \\
S6 & $100(+1)$ & $25(-1)$ & $50(+1)$ \\
S7 & $50(-1)$ & $50(+1)$ & $50(+1)$ \\
S8 & $100(+1)$ & $50(+1)$ & $50(+1)$
\end{tabular}

${ }^{¥}$ Number in bracket represents the coded value 
Table 2 Analysis of variance (ANOVA) for $2^{3}$ full factorial design on hydrodynamic diameter (at day 14)

\begin{tabular}{ccccc}
\hline & Sum of squares & $\boldsymbol{d} \boldsymbol{f}$ & $\boldsymbol{F}$-value & $\boldsymbol{P}$ value \\
\hline Model & 99861.59 & 3 & 26.13 & $0.0043^{*}$ \\
A & 42748.88 & 1 & 33.56 & $0.0044^{*}$ \\
B & 7626.12 & 1 & 5.99 & 0.0707 \\
AB & 49486.58 & 1 & 38.85 & $0.0034^{*}$ \\
\hline
\end{tabular}

A - Stearic acid, B - Lutrol $®$ micro 68, C - Phosal ${ }^{\circledR} 53 \mathrm{MCT}$

* Significance level $p<0.05$ 
Table 3 Analysis of variance (ANOVA) for $2^{3}$ factorial design on PDI (day 14)

\begin{tabular}{lcccc}
\hline & Sum of squares & $\boldsymbol{d} \boldsymbol{f}^{*}$ & $\boldsymbol{F}$-value & $\boldsymbol{P}$ value \\
\hline Model & 0.046 & 5 & 267.18 & $0.0037^{*}$ \\
$A$ & 0.018 & 1 & 527.01 & $0.0019^{*}$ \\
$B$ & $1.805 \times 10^{-4}$ & 1 & 5.27 & 0.1486 \\
$C$ & 0.014 & 1 & 412.03 & $0.0024^{*}$ \\
$A B$ & 0.012 & 1 & 337.28 & $0.0030^{*}$ \\
$A C$ & $1.861 \times 10^{-3}$ & 1 & 54.32 & $0.0179^{*}$
\end{tabular}

A - Stearic acid, B - Lutrol ${ }^{\circledR}$ micro 68, C - Phosal ${ }^{\circledR} 53$ MCT

* Significance level $p<0.05$ 
Table 4 Entrapment efficiency and drug loading of DST-NLCs at day $1(n=3)$

\begin{tabular}{cccccc}
\hline Formulation & $\begin{array}{c}\text { Stearic } \\
\text { acid (mg) }\end{array}$ & $\begin{array}{c}\text { Lutrol® } \\
\text { micro 68 } \\
(\mathbf{m g})\end{array}$ & $\begin{array}{c}\text { Phosal® 53 } \\
\text { MCT (mg) }\end{array}$ & $\begin{array}{c}\text { EE (\%) } \\
(\mathbf{m e a n} \pm \\
\text { SD) }\end{array}$ & $\begin{array}{c}\text { DL (\%) } \\
\text { (mean } \pm \\
\text { SD) }\end{array}$ \\
\hline S1 & 50 & 25 & 25 & $79.6 \pm 10.3$ & $4.40 \pm 0.58$ \\
S2 & 100 & 25 & 25 & $81.7 \pm 20.3$ & $3.31 \pm 0.75$ \\
S3 & 50 & 50 & 25 & $63.2 \pm 21.8$ & $2.98 \pm 0.61$ \\
S4 & 100 & 50 & 25 & $97.6 \pm 2.4$ & $3.27 \pm 0.07$ \\
S5 & 50 & 25 & 50 & $80.0 \pm 0.6$ & $2.49 \pm 0.65$ \\
S6 & 100 & 25 & 50 & $97.7 \pm 1.2$ & $3.09 \pm 0.35$ \\
S7 & 50 & 50 & 50 & $64.8 \pm 7.7$ & $2.09 \pm 0.32$ \\
S8 & 100 & 50 & 50 & $92.5 \pm 5.6$ & $2.66 \pm 0.24$ \\
\hline EE - entrapment efficiency, DL - drug loading & & &
\end{tabular}


Table 5 Analysis of variance (ANOVA) for $2^{3}$ full factorial design experiment variables' effect on entrapment efficiency

\begin{tabular}{ccccc}
\hline & Sum of squares & $\boldsymbol{d} \boldsymbol{f}^{*}$ & $\boldsymbol{F}$-value & $\boldsymbol{P}$ value \\
\hline Model & 1116.71 & 3 & 10.46 & $0.0230^{*}$ \\
$A$ & 838.45 & 1 & 23.56 & $0.0083^{*}$ \\
$B$ & 54.80 & 1 & 1.53 & 0.2832 \\
$A B$ & 223.66 & 1 & 6.28 & 0.0663 \\
\hline A - Stearic acid, B - Lutrol ${ }^{\circledR}$ F68, C - Phosal® 53 MCT, *significance level $p<0.05$
\end{tabular}


Table 6 Size distribution and surface charge of uncoated DST-NLCs and coated with CSOSA or CSO

\begin{tabular}{|c|c|c|c|c|}
\hline Storage condition & DST-NLCs & $\begin{array}{c}\text { DST-NLCs } \\
5 \% \text { CSO-SA }\end{array}$ & $\begin{array}{c}\text { DST-NLCs } \\
10 \% \text { CSO-SA }\end{array}$ & $\begin{array}{l}\text { DST-NLCs } \\
5 \% \mathrm{CSO}\end{array}$ \\
\hline \multicolumn{5}{|l|}{ Day 1 (Initial) } \\
\hline Particle size $(\mathrm{nm})$ & $187.6 \pm 7.0$ & $220.1 \pm 11.9$ & $230.1 \pm 8.2$ & $208.4 \pm 1.6$ \\
\hline PDI & $\begin{array}{c}0.117 \pm \\
0.008\end{array}$ & $\begin{array}{c}0.149 \pm \\
0.024\end{array}$ & $0.147 \pm 0.026$ & $0.167 \pm 0.025$ \\
\hline $\begin{array}{l}\text { Zeta potential } \\
(\mathrm{mV})\end{array}$ & $-18 \pm 0.9$ & $+26 \pm 1.1$ & $+30 \pm 1.2$ & $+22 \pm 2.1$ \\
\hline \multicolumn{5}{|l|}{ Day 30 at $4^{\circ} \mathrm{C}$} \\
\hline Particle size (nm) & $216.8 \pm 6.0$ & $239.0 \pm 24.3$ & $241.9 \pm 7.5$ & Aggregation \\
\hline PDI & $\begin{array}{c}0.132 \pm \\
0.017\end{array}$ & $\begin{array}{c}0.193 \pm \\
0.064\end{array}$ & $0.213 \pm 0.006$ & Aggregation \\
\hline $\begin{array}{l}\text { Zeta potential } \\
(\mathrm{mV})\end{array}$ & $-17.2 \pm 2.6$ & $33.9 \pm 1.8$ & $33.8 \pm 1.8$ & Aggregation \\
\hline \multicolumn{5}{|l|}{ Day 30 at $25^{\circ} \mathrm{C}$} \\
\hline Particle size (nm) & $435.3 \pm 32.0$ & $443.6 \pm 62.9$ & Aggregation & Aggregation \\
\hline PDI & $\begin{array}{c}0.208 \pm \\
0.036\end{array}$ & $\begin{array}{c}0.233 \pm \\
0.032\end{array}$ & Aggregation & Aggregation \\
\hline $\begin{array}{l}\text { Zeta potential } \\
(\mathrm{mV})\end{array}$ & $-17.0 \pm 0.7$ & $24.0 \pm 1.0$ & Aggregation & Aggregation \\
\hline \multicolumn{5}{|l|}{ Day 60 at $4^{\circ} \mathrm{C}$} \\
\hline Particle size (nm) & $228.5 \pm 6.8$ & $\begin{array}{c}243.8 .0 \pm \\
18.8\end{array}$ & $259.8 \pm 4.2$ & Aggregation \\
\hline PDI & $\begin{array}{c}0.128 \pm \\
0.004\end{array}$ & $\begin{array}{c}0.155 \pm \\
0.025\end{array}$ & $0.215 \pm 0.020$ & Aggregation \\
\hline $\begin{array}{l}\text { Zeta potential } \\
(\mathrm{mV})\end{array}$ & $-17.2 \pm 2.6$ & $32.2 \pm 10.4$ & $29.4 \pm 5.6$ & Aggregation \\
\hline \multicolumn{5}{|l|}{ Day 60 at $25^{\circ} \mathrm{C}$} \\
\hline Particle size $(\mathrm{nm})$ & $435.3 \pm 32.0$ & $578.2 \pm 27.0$ & Aggregation & Aggregation \\
\hline PDI & $\begin{array}{c}0.208 \pm \\
0.036\end{array}$ & $\begin{array}{c}0.274 \pm \\
0.113\end{array}$ & Aggregation & Aggregation \\
\hline $\begin{array}{l}\text { Zeta potential } \\
(\mathrm{mV})\end{array}$ & $-18.9 \pm 1.6$ & $20.0 \pm 1.6$ & Aggregation & Aggregation \\
\hline
\end{tabular}




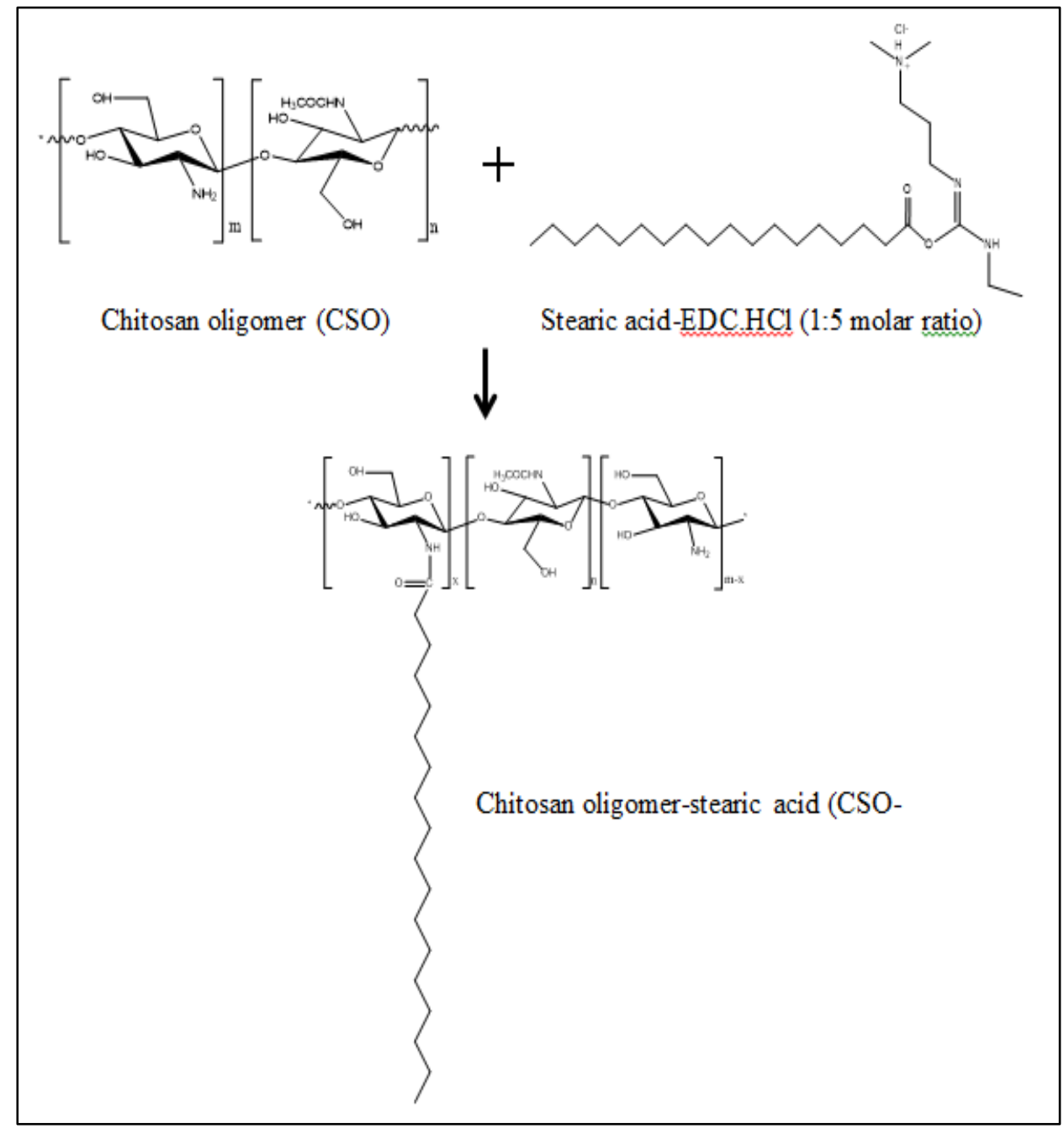

Fig. 1 Conjugation of chitosan oligomer with stearic acid. 

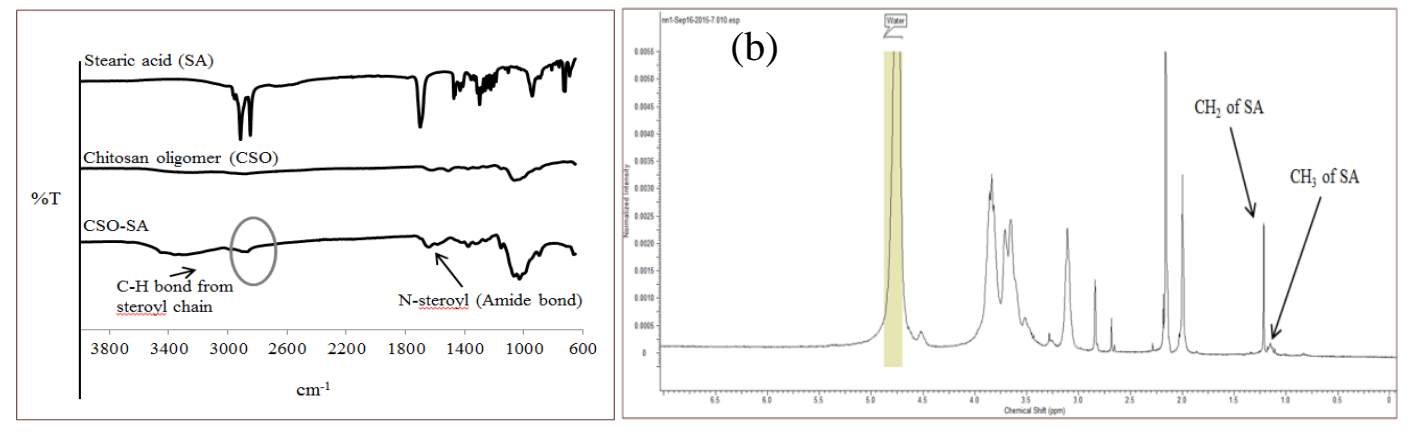

Fig. 2 FTIR (a) and ${ }^{1}$ H NMR (b) spectra of CSO-SA. 


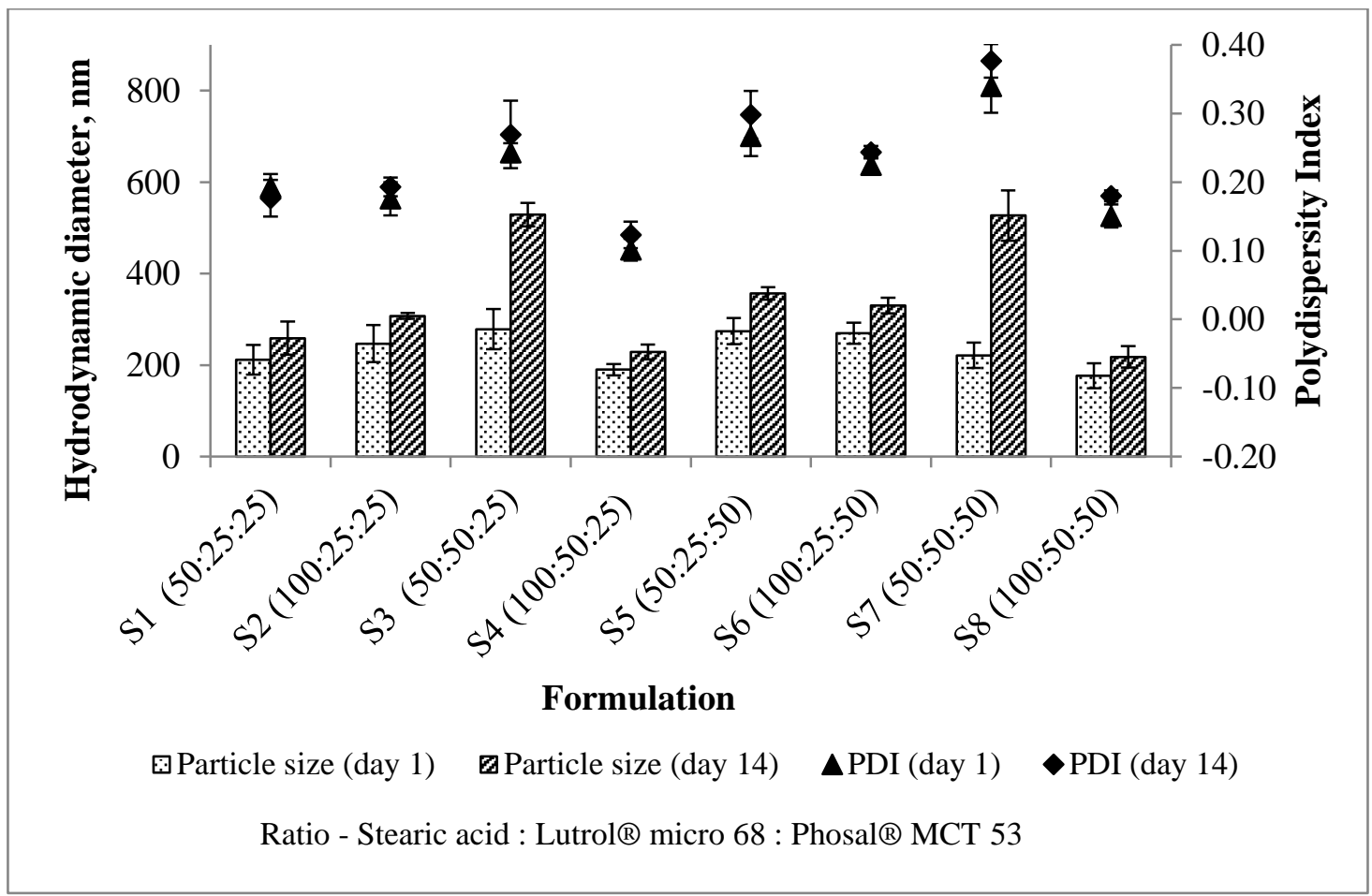

Fig. 3 Hydrodynamic diameter (nm) and particle size distribution for formulations of DST-NLCs (day 1 and day 14, $n=3 \pm$ s.d.). 

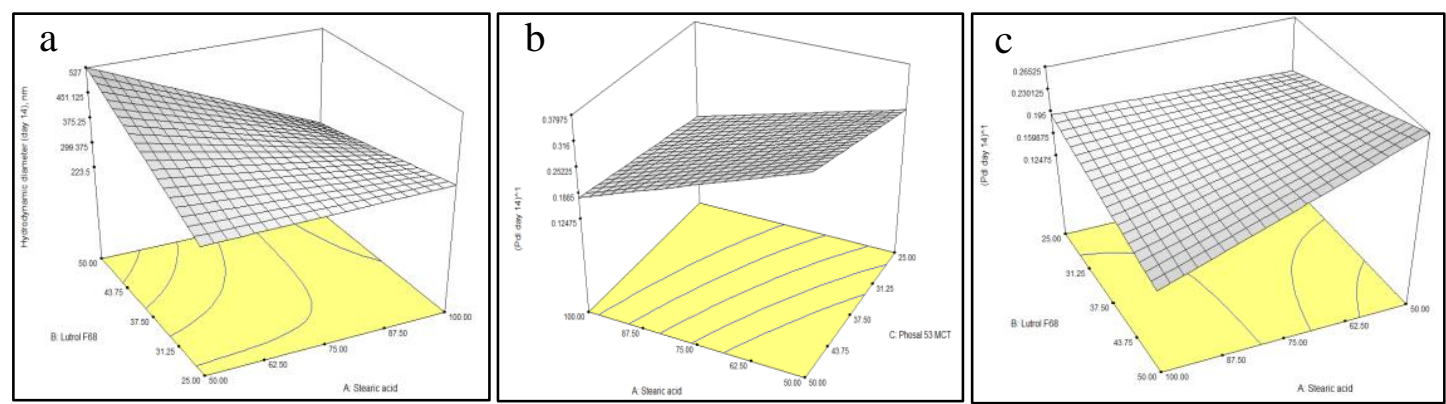

Fig. 4 3D-surface graph of interaction on hydrodynamic diameter (a) and polydispersity index (b and c) at day 14. 


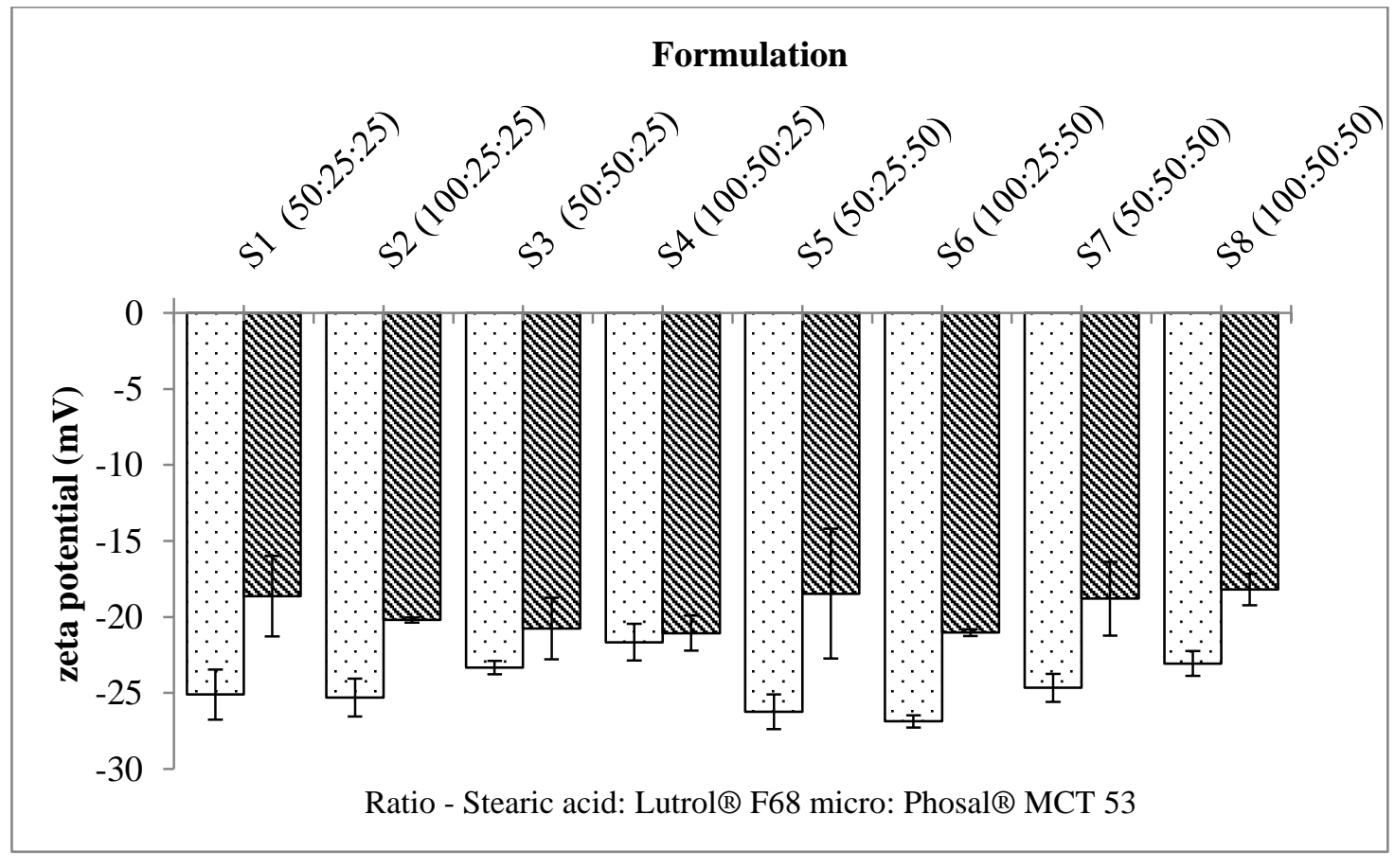

Fig. 5 Zeta potential of formulations of DST-NLCs at day 1 and day 14 (n=3 \pm s.d.). 


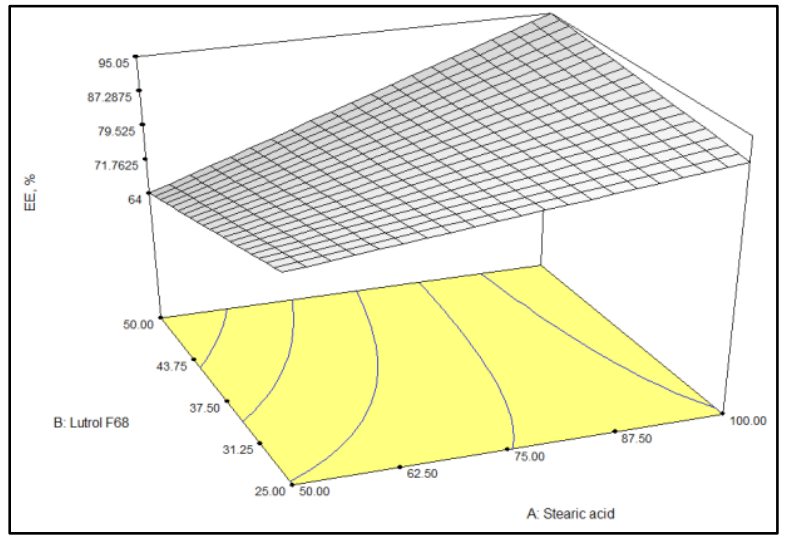

Fig. 6 3D-surface graph of interaction between stearic acid $(A)$ and Lutrol ${ }^{\circledR}$ micro $68(B)$ on entrapment efficiency. 

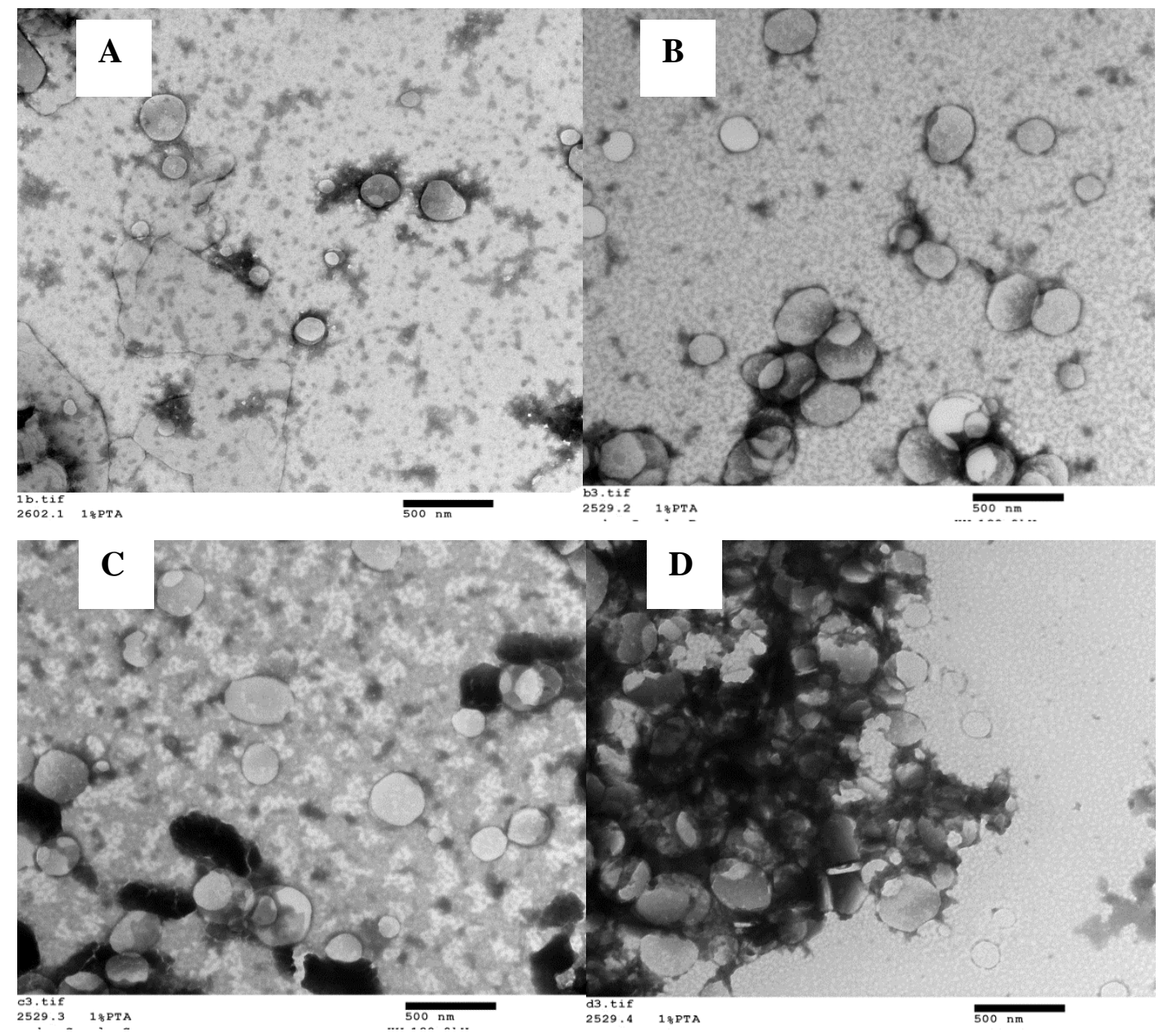

Fig. 7 TEM Morphology of DST-NLCs, uncoated (A), coated with; 5\% CSO (B), $5 \%$ CSO-SA (C) and 10\% CSO-SA (D). 


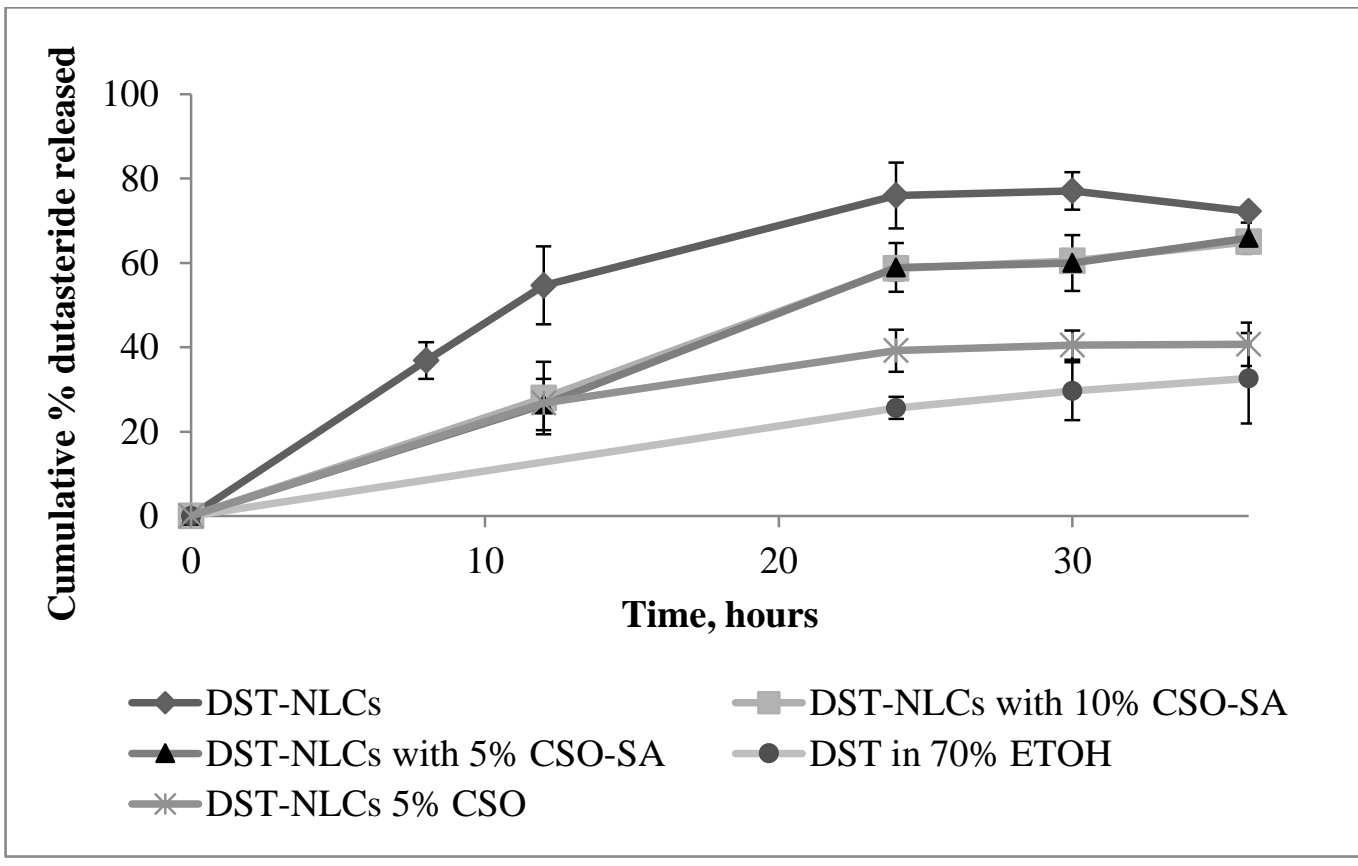

Fig. 8 Drug release from different DST-NLCs formulations and control (dutasteride in ethanol) $(n=3 \pm$ s.d.). 


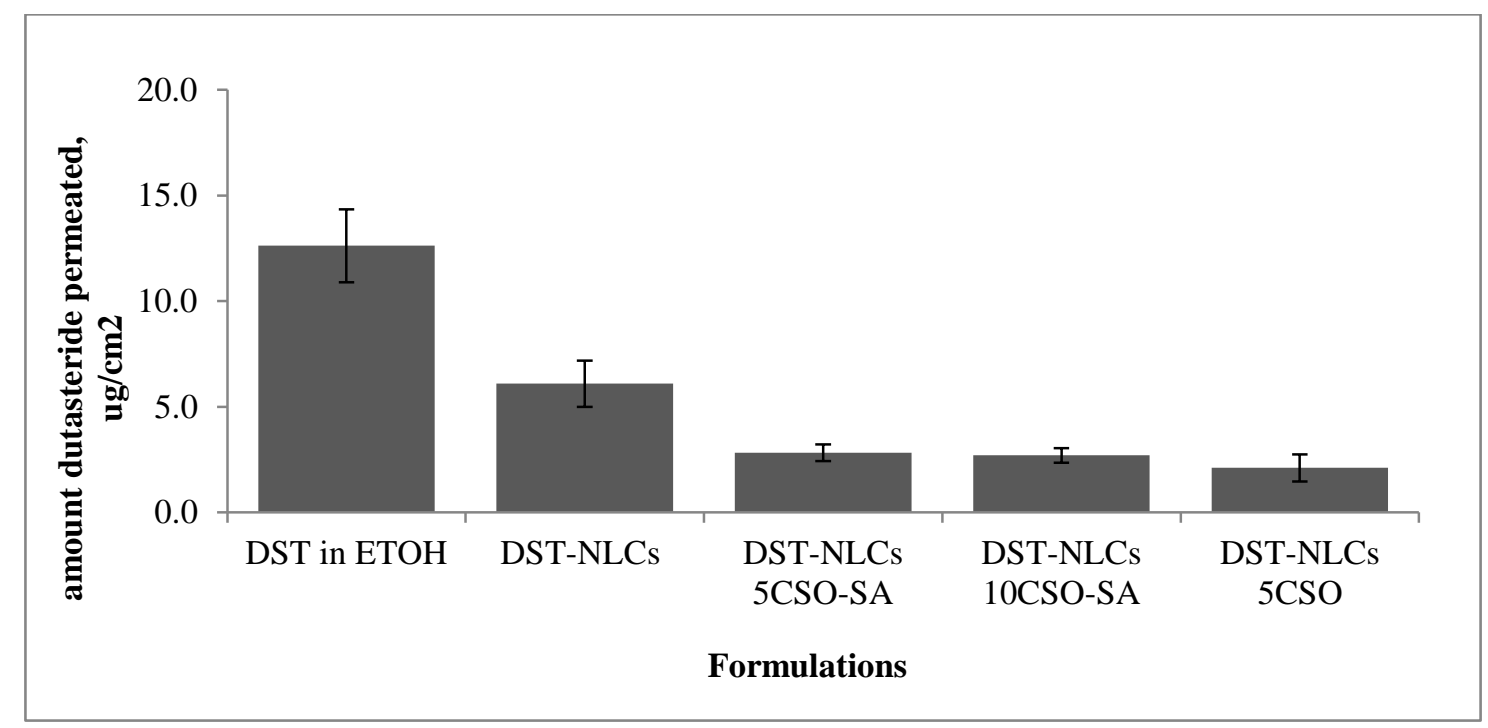

Fig. 9 Amount of dutasteride permeated in the skin after 48 hours $(n=4 \pm$ s.d.). 


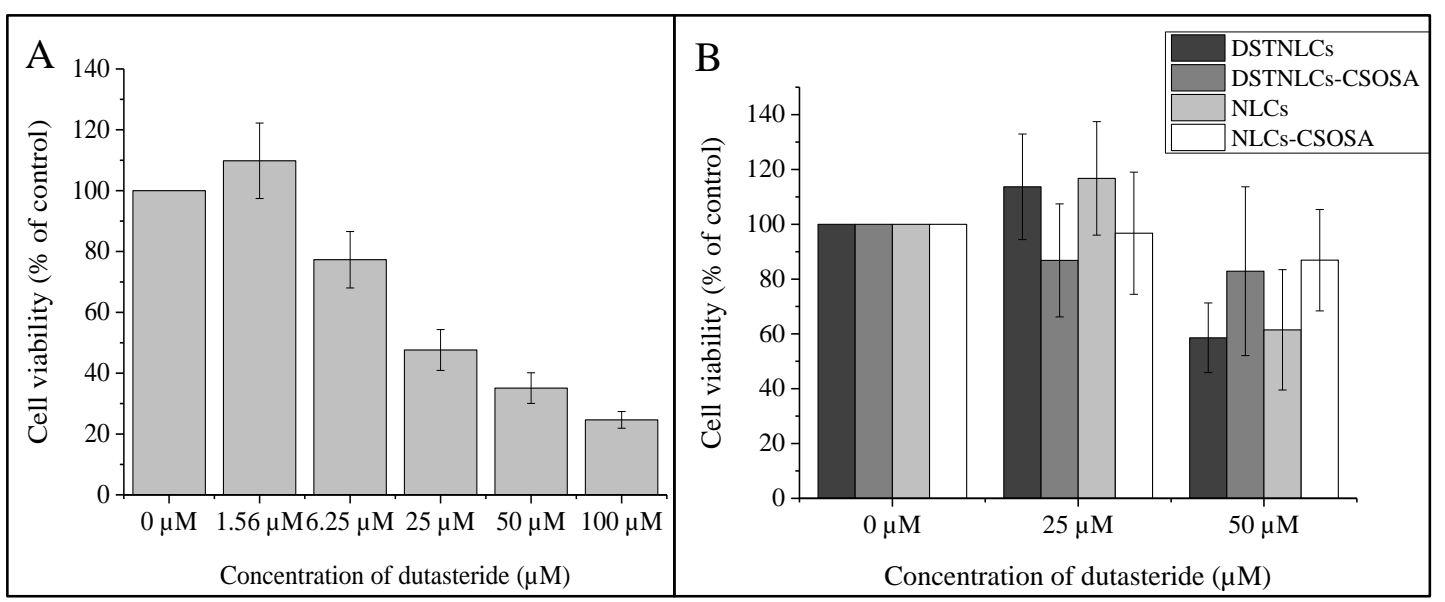

Fig. 10 Cytotoxicity of dutasteride alone (A), DST-NLCs uncoated and coated with CSO-SA and empty NLCs/NLCs-CSOSA (B) on hair follicle dermal papilla cells ( $n=4 \pm$ s.d.). 